\title{
ANN Based Broken Rotor Bar Fault Detection in LSPMS Motors
}

\author{
Baradieh $\mathrm{K}^{*}$, Al-Hamouz $\mathrm{Z}$ and Abido $\mathrm{M}$
}

Electrical Engineering Department, King Fahd University of Petroleum and Minerals, Saudi Arabia

\begin{abstract}
Line Start Permanent Magnet Synchronous Motors (LSPMSMs) combine the high efficiency of the permanent magnet synchronous motors (PMSM) with the ease of use, simplicity in design and high starting capability of the induction motors (IMs). Due to the rapidly growing usage of this relatively new motor, proposing a diagnostics method for broken rotor bar fault is necessity. In this paper, a diagnostics technique based on Artificial Neural Network (ANN) was developed to detect the broken bars fault in LSPMSM using Singular Value Decomposition (SVD) in order to extract distinguishing features from the stator phase current. This distinguishing attributes were proposed to be the inputs to the built neural network.
\end{abstract}

Keywords: LSPMSM; Broken bar; Stator current signature; Fault; FEM; Coupled magnetic circuit; Winding function; JMAG; ANN; SVD

\section{Introduction}

Motors are ubiquitous in everyday life and have wide ranging applications, such as industrial, commercial and residential utilization. Statistics indicate that electrical motors account for about two-thirds of the total industrial power consumption in each society. Because of the unlimited number of electric motor applications, there are over 700 million motors of various sizes in operation across the world [1]. Induction motors constitute by far the largest portion of electrical motors in the market. However, motors that are more efficient began to appear as an alternative. In the last few years, "Line Start Permanent Magnet Synchronous Motor (LSPMSM)" emerged as a powerful candidate in the motor industry, and has been promoted for industrial, commercial and residential applications. This motor has many desirable features that will likely expand its market size. Therefore, LSPMSM is expected to replace the currently utilized motors, such as induction motors. On the other hand, it is well known that the AC motors are susceptible to many faults types such as broken rotor bars fault. Motor failures may result in catastrophic events, including production shutdowns. Such shutdowns are costly in terms of lost production time, maintenance costs and wasted in the raw materials. For these reasons, studying the LSPMSM and finding a reliable diagnostic and monitoring tool under broken bar fault condition is urgent need.

Recently, monitoring machine faults has constituted an interest of research teams. Broken rotor bars are a common fault in AC machines. Dedicated diagnostic techniques and systems are demanded to detect an upcoming machine defect as early as possible. Consequently, there is an extensive body of work on the monitoring and detection techniques of the broken rotor bars in induction motors. For example, Hwang [2] proposed an algorithm for detecting the broken bar faults in induction motors based on the dimension order of the frequency signal, which was called Frequency Signal Dimension Order (FSDO). FSDO was used to analyze the stator current signal, as well as to estimate the fault type based on the resultant frequency. The fault decision model analyzed the data derived from FSDO to decide whether there is a fault or not based on certain indices. This work was verified by comparing simulation and experimental results pertaining to a 3-phase, squirrel cage induction motor. The main disadvantage of this work was FSDO estimator, which gave a good performance for steady-state operations only. Carlos [3] demonstrated the effect of the broken bar fault on the stator current signature in the induction motor, and then used the "zero setting protection element" method to detect the occurrence of the broken bar fault under different loading levels. This work has successfully detected the broken rotor bar fault under different loading levels with high accuracy.

Another method for diagnostics of broken rotor bar in induction motors was introduced by Zarei et al. [4], the broken bars are monitored based on the artificial neural network using "particle swarm optimization" in training process that work was performed in two stages, commencing with designing a filter to remove noise components from the faulty motor current. The least squares algorithm was also used to find the filter coefficients. In the second stage, a neural network was trained to extract the fault classifications. The output of this network was utilized to classify the state of the motor into four types: healthy bar, cracked on the bar, one and two broken bars.

Guo-Liang [5] proposed a method to diagnose the broken bar faults in induction motors based on "empirical decomposition method". In that work, several intrinsic mode functions (IMF) were used to decompose and analyze the starting current, before applying Hilbert transform for frequency analysis. As a result of this work, and because of the symmetry in the rotor, broken bar fault caused a frequency component (1-2s)f, where $s$ denotes slip and $f$ pertains to source frequency. Using Hilbert transform, several researches attempted developing diagnostics methods for broken rotor bar in induction motors under no load conditions. For example, Aydin [6] utilized sliding window for several periods. That method was used to detect one or two broken bars only under no load and with a supply voltage greater than $260 \mathrm{~V}$. The entropy of the incoming data was calculated and compared with some threshold as the first stage. In the second stage, the fault size was determined, i.e., the number of faulty bars. High accurate results were obtained using this method with little computation cost in short time, which were tested under limited conditions.

*Corresponding author: Baradieh K, Electrical Engineering Department, King Fahd University of Petroleum and Minerals, Saudi Arabia, Tel: 966533591540; E-mail: Khalid.baradia@outlook.com

Received July 27, 2018; Accepted September 03, 2018; Published September 10, 2018

Citation: Baradieh K, Al-Hamouz Z, Abido M (2018) ANN Based Broken Rotor Bar Fault Detection in LSPMS Motors. J Electr Electron Syst 7: 273. doi: 10.4172/23320796.1000273

Copyright: (c) 2018 Baradieh K, et al. This is an open-access article distributed under the terms of the Creative Commons Attribution License, which permits unrestricted use, distribution, and reproduction in any medium, provided the original author and source are credited. 
Authors of many previous studies have found that the faulty motors contain two sideband frequencies on the stator current spectrum. Thus, transformation methods such as Fourier, Fast Fourier, Discrete-time Fourier and Wavelet transform have been used to achieve that frequency band. Chen [7] utilized these findings to detect these frequency bands, but because of the limitations in the previously mentioned transformation-where the detection accuracy of broken rotor bar would be affected depending on the loading condition, or even the length of the processed data records-the author used Prony spectrum analysis method to overcome these limitations. The main advantage of that method was its ability to overcome the data window length restriction, along with its reliability under light or varying loads. Both mathematical and simulation models were built to implement the effect of broken rotor bars in induction motors by relating its effect to the stator current, which was represented by two sideband frequencies. The author has reported that the amplitude of the frequency component increased as the number of broken bars increased, resulting in a series of harmonies.

Shashi [8], Dhara [9] and Siddiqui [10] proposed methods to detect broken bars fault based on the "Wavelet transform" using different mother wavelet. These models received the phase stator current as an input, after which the authors applied daubechies (db8, db9, db10), and symlet (sym7, sym8) mother wavelets to analyze the stator current components. The results were compared to determine the optimal mother wavelet in detecting the broken rotor bars, and to determine the number of faulty bars in the motor. It can be concluded from these studies that, as the load or the number of broken bars increases, the harmonic components will be increased.

On the other hand, there has been relatively little research for detecting the broken bar fault in the LSPMSM. Recently, four research articles addressed the behavior of LSPMSM under broken bar conditions. Mehrjou et al. [11,12] used ANSYS Maxwell software to study the performance of the motor under broken bar fault condition. The authors concentrated on the stator current and air-gap signatures to investigate the possibility of broken bar occurrence because of its easy measurability, reliability and high accuracy. Hilbert transform which is the convolution between the original signal (real time stator current) and the function $1 /$ /лt were applied to extract the envelop of the stator current signals. Fourier Transform has been applied on the function 1/ лt, which can be viewed as a filter for unity amplitude and \pm 90 phase depending on the frequency sign of the input signal. The analytic signal, which is created by adding both real and its Hilbert transform signals has been used to filter the negative frequencies of the stator current signals. After the signal envelops were obtained at different conditions, many statistical features were examined on the obtained envelops for broken bar fault detection. Such features are the Mean, RMS, Energy, Peak index, Tolerance index, etc. The statistical features were compared for healthy and faulty motor. The authors indicated that the load effect in the starting time should be considered in fault detection in this motor type, unlike induction machines. Moreover, the results showed that only seven features from the proposed twelve features could be used in fault detection. These features are Mean, RMS, RSS, Shape factor, Skewness and Kurtosis index. Other features could not be used because of the occurred overlap between healthy and faulty trends of the current signal. In addition, the same authors in $[13,14]$ have analyzed the stator current envelope under broken bar condition using statistical features in time domain as a fault diagnosis method. Following up, they applied some statistical features in time domain as a fault diagnostics method.
Based on the literature review, it is evident that diagnostics of the broken bar fault based on artificial intelligence and mathematical modelling of LSPMSM has not been performed thus far. Therefore, in this work, a diagnosis method of the broken rotor bar faults in the LSPMSM using neural network will be developed. The accuracy of the developed model will be tested through different tests and under different number of broken bars and loading levels.

\section{Dynamic Model of LSPMSM}

In this section, a dynamic mathematical model of LSPMSM under healthy and broken bar fault conditions are presented.

\section{Mathematical modelling of healthy LSPMSM}

A mathematical model of healthy LSPMSM has been developed in the literature $[15,16]$. These models are built based on the symmetry in the resistance and inductance matrices. Equations (1) to (5) describe the mathematical model of the healthy LSPMSM.

$\left[\begin{array}{l}V_{q s} \\ V_{d s} \\ V_{q r} \\ V_{d r}\end{array}\right]=\left[\begin{array}{cccc}r_{s} & 0 & 0 & 0 \\ 0 & r_{s} & 0 & 0 \\ 0 & 0 & r_{q r}^{\prime} & 0 \\ 0 & 0 & 0 & r_{d r}^{\prime}\end{array}\right]\left[\begin{array}{c}I_{q s} \\ I_{d s} \\ I_{q r}^{\prime} \\ I_{d r}^{\prime}\end{array}\right]+\frac{d}{d t}\left[\begin{array}{c}\lambda_{q s} \\ \lambda_{d s} \\ \lambda_{q r}^{\prime} \\ \lambda_{d r}^{\prime}\end{array}\right]+\left[\begin{array}{c}\omega_{r} \lambda_{d s} \\ -\omega_{r} \lambda_{q s} \\ 0 \\ 0\end{array}\right]$

$\left[\begin{array}{l}\lambda_{q s} \\ \lambda_{d s} \\ \lambda_{q r}^{\prime} \\ \lambda_{d r}^{\prime}\end{array}\right]=\left[\begin{array}{cccc}L_{l s}+L_{m q} & 0 & L_{m q} & 0 \\ 0 & L_{l s}+L_{m d} & 0 & L_{m d} \\ L_{m q} & 0 & L_{l l}^{\prime}+L_{m q} & 0 \\ 0 & L_{m d} & 0 & L_{l r}^{\prime}+L_{m d}\end{array}\right]\left[\begin{array}{c}I_{q s} \\ I_{d s} \\ I_{q r}^{\prime} \\ I_{d r}^{\prime}\end{array}\right]+\left[\begin{array}{c}0 \\ \lambda_{m}^{\prime} \\ 0 \\ \lambda^{\prime}\end{array}\right]$

$\omega_{r}(t)=\left(\frac{P}{2 J}\right) \int\left(T_{e m}+T_{m e c h}-T_{\text {damp }}\right) d t$

$T_{e m}=\left(\frac{3}{2}\right)\left(\frac{P}{2}\right)(\underbrace{L_{m d} I^{\prime}{ }_{d r} i_{q s}}_{\text {Cage-torque }}+\underbrace{\lambda^{\prime}{ }_{m} I_{q s}}_{P M \text {-torque }}+\underbrace{\left(L_{m d}-L_{m q}\right) I_{d s} I_{q s}}_{\text {Re luctance-torque }})$

$\lambda_{m}^{\prime}=L_{m d} I_{m}^{\prime}$

Where the primed quantities indicate that, the values pertain to the stator side. The Subscripts $s, r$ refers to the stator and rotor, respectively. $\left(V_{q s}, V_{d s}\right),\left(V_{q r}, V_{d r}\right),\left(I_{q s}, I_{d s}\right),\left(I_{q r}^{\prime}, I_{d r}^{\prime}\right),\left(\lambda_{q s}, \lambda_{d s}\right)$ and $\left(\lambda_{q r^{\prime}}^{\prime}\right.$ $\left.\lambda_{d r}^{\prime}\right)$ are the quadrature and direct axes of the stator and rotor voltages, currents and flux linkages, respectively. $r_{s}$ is the stator resistance and $\left(r_{q r}^{\prime}, r_{d r}^{\prime}\right)$ are the rotor resistances in the $q$ and $d$ reference frames, respectively. $\omega_{r}$ is the angular speed. $\left(L_{l s}, L_{l r}^{\prime}\right)$ are the stator and rotor leakage inductances, respectively. $\left(L_{m q}, L_{m d}\right)$ are the mutual inductances in $q$ and $d$ reference frames, respectively. $\left(T_{e m}, T_{\text {load }}\right.$ and $\left.T_{\text {damp }}\right)$ are the motor electromechanical torque, mechanical torque applied by the load and the damping torque in the direction opposite to the rotor rotation, respectively. Finally, $J$ denotes the rotor inertia and $P$ is the number of motor poles.

Equation (1) describes the stator and rotor electric voltages in the $q d$ reference frame, while Equation (2) provides the stator and rotor fluxes in the $q d$ reference frame. In addition, the rotor angular rotation and electromagnetic torque of the LSPMSM are given in Equations (3) and (4), respectively. The PM inductance can be combined with the d-axis mutual inductance of the stator $\left(L_{m d}\right)$ [15]. Therefore, the magnetizing flux of the PM is defined in (5), where $I_{m}$ is the equivalent magnetizing current of the PM. 
On the other hand, a dynamic mathematical model, which takes into consideration asymmetrical conditions such as broken bars, was developed based on the winding function approach and coupled magnetic circuit theory in the $q d$ reference frame.

\section{Mathematical modelling of a faulty LSPMSM under broken bar condition}

The LSPMSM stator consist of three sinusoidally distributed windings displaced by 120 degree with $N_{s}$ turns. The rotor cage contains $N_{r}$ bars, forming $N_{r}$ loops; each contains two adjacent rotor bars connected by two end-rings. For modelling purposes of the LSPMSM, rotor eddy current losses of the PM are ignored since the ohmic resistance of the magnet material is 80 times greater than the copper losses. In addition, the rotor airgap is assumed to be uniform and the inter-bar currents are ignored [15]. It is documented in the pertinent literature that LSPMSM is a highly symmetrical motor; thus, any fault will cause a degree of asymmetry in its parameters. However, broken rotor bar faults will cause asymmetry in the rotor resistance and inductance matrices. In addition, such fault type will affect the mutual coupling inductance matrices between rotor and stator. In order to study the effect of the broken bar fault condition on the LSPMSM, the proposed model should be modified to include the effect of each rotor bar. Since the rotor includes $N_{r}$ loops, and each loop includes two bar leakage inductances, two bar resistances, two end-ring leakage inductances and two end ring resistances, then the electric (voltage mesh) equation governing the $j^{\text {th }}$ loop is defined as [17]:

$$
0=2\left(R_{b}+R_{e}\right) I_{j}-R_{b} I_{(j-1)}-R_{b} I_{(j+1)}+\frac{d}{d t} \lambda_{r j}
$$

where $R_{b}$ and $R_{e}$ are the rotor bar and end-ring resistances, respectively. Subscripts $r, j$ denotes the rotor and the rotor loop number, respectively. $I_{j}, \lambda_{r}$ are the rotor bar current and flux, respectively. Thus, the general expression of the rotor electric equation can be written as:

$$
0=R_{r} I_{r}+\frac{d}{d t} \lambda_{r}
$$

where, $R_{r}$ is an $N_{r} \times N_{r}$ equivalent rotor resistance matrix, described as follows:

$$
R_{r}=\left[\begin{array}{cccc}
2\left(R_{b}+R_{e}\right) & -R_{b} & \ldots & -R_{b} \\
-R_{b} & 2\left(R_{b}+R_{e}\right) & \ldots & 0 \\
\vdots & \vdots & \ddots & \vdots \\
-R_{b} & 0 & \ldots & 2\left(R_{b}+R_{e}\right)
\end{array}\right]
$$

The rotor flux is a combination of the self-flux $\left(L_{r}\right)$, which is coming from the rotor loops current (self and mutual), the mutual flux between stator coils and rotor loops $\left(L_{m(r s)}\right)$ and the PM flux $\left(\lambda_{p m}^{\prime}\right)$, which can be expressed as follows:

$$
\lambda_{r}=L_{r} I_{r}+L_{m(r s)} I_{s}+\lambda_{p m}^{\prime}
$$

The total inductance of the $j^{\text {th }}$ rotor loop (loop self-inductance) is equal to the sum of its principal inductance $\left(L_{r p}\right)$, leakage inductance of the two bars in the loop $\left(L_{b}\right)$ and the leakage inductance of the two end rings closing the loop $\left(L_{e}\right)$, which can be described as follows:

$$
L_{r r}=\left(L_{r p}+2\left(L_{b}+L_{e}\right)\right)
$$

The mutual inductance between two adjacent meshes $\left(L_{r k(k-1)}=\right.$ $\left.L_{r k(k+1)}\right), k \in\left\{1,2 \ldots N_{r}\right\}$ can be defined as follows:

$$
L_{r k(k \pm 1)}=M_{r r}-L_{b}
$$

where $M_{r r}$ is the mutual magnetic coupling between two rotor loops. Therefore, the general expression of the rotor cage inductance can be rearranged in $N_{r} \times N_{r}$ matrix, as follows:

$$
L r=\left[\begin{array}{ccclc}
L_{r p}+2\left(L_{b}+L_{e}\right) & M_{r r}-L_{b} & M_{r r} & \ldots & L_{1 N r}-L_{b} \\
M_{r r}-L_{b} & L_{r p}+2\left(L_{b}+L_{e}\right) & M_{r r}-L_{b} & \ldots & M_{r r} \\
\vdots & \vdots & \vdots & \ddots & \vdots \\
M_{r r}-L_{b} & M_{r r} & M_{r r} & \ldots & L_{r p}+2\left(L_{b}+L_{e}\right)
\end{array}\right]
$$

One further step is required for the simulation purposes, in which rotor parameters are transformed from the $a b c$ to the $q d$ reference frame using multi-phase to two phase $\left(K_{\mathrm{r}}\right)$ transformation matrix. Therefore, the rotor electrical equation in $q d$ reference frame can be written as follows:

$$
\begin{aligned}
& V_{q d r}=[0]=K_{r} R_{r} K_{r}^{-1} I_{q d r}+K_{r} \frac{d}{d t}\left(K_{r}^{-1} \lambda_{q d r}\right) \\
& 0=R_{q d r} I_{q d r}+\frac{d}{d t} \lambda_{q d r}
\end{aligned}
$$

In addition, rotor flux equation in the $q d$ reference frame can be expressed as follows:

$$
\lambda_{q d r}=L_{q d r} I_{q d r}+L_{m q d} I_{q d s}+\lambda_{q d, p m}^{\prime}
$$

\section{Inductances calculation}

In this paper, winding function Approach (WFA) was used to derive the inductance formulas of the stator and rotor. WFA is used to describe the coils along the airgap geometrically. According to the pertinent literature, and for uniform airgap, the mutual inductance between any two windings $x$ and $y$ is given by $[18,19]$ :

$$
L_{x y}=\frac{\mu_{o} l r}{g} \int_{0}^{2 \pi} W_{x}\left(\theta_{r}, \gamma\right) W_{y}\left(\theta_{r}, \gamma\right) d \gamma
$$

where, $\mu_{0}$ is the space permeability, $r$ is the average radius of the airgap, $g$ is the radial airgap length, $l$ is the motor stack length, $\theta_{r}$ is the angle between rotor and stator and $\gamma$ is the angle along the airgap. $W_{x}$ and $W_{y}$ denote the winding function of the $x$ and $y$ windings, respectively. The motor utilized in the present study has a 3-phase stator, each with $N$ windings. Thus, in order to obtain a smooth MMF; a sinusoidal distribution of the stator windings along the airgap should be used. The normalized stator phase $a$ winding function can be described as follows $[18,19]$ :

$$
W_{s a}(\gamma)=\frac{N_{s}}{2} \cos (\gamma)
$$

In addition, and as mentioned previously, rotor cage is modeled as $N_{r}$ magnetically coupled loops. Since the rotor-bars are equidistantly placed along the rotor circumference, which is non-sinusoidal distribution, then non-sinusoidal distribution of the loop windings was used. In order to calculate the rotor cage inductances, the winding function of the $i^{\text {th }}$ rotor loop can be expressed as follows $[18,19]$ :

$$
W_{r i}\left(\theta_{r}\right)=\left\{\begin{array}{l}
-\frac{\alpha_{r}}{2 \pi}, 0 \leq \theta_{r} \leq \theta_{i} \\
1-\frac{\alpha_{r}}{2 \pi}, \theta_{i} \leq \theta_{r} \leq \theta_{i+1} \\
-\frac{\alpha_{r}}{2 \pi}, \theta_{i+1} \leq \theta_{r} \leq 2 \pi
\end{array}\right.
$$


where $W_{r i}$ is the rotor loop winding function, and $\theta_{i}$ and $\theta_{i+1}$ are the positions of two adjacent rotor bars that form the rotor loop.

Consequently, the stator flux linkage due to the stator current is caused by self-inductance of the stator coils, which is the sum of the stator phase leakage and the magnetizing inductances, given by:

$$
L_{s a}=L_{s b}=L_{s c}=L_{l s}+L_{m s i}
$$

where $L_{l s}$ is the stator leakage inductance, and $L_{m s i}, i \in\{a, b, c\}$ is the stator phase magnetizing inductance calculated by substituting Equation (17) into Equation (16). For instance, the magnetizinginductance of the phase $a$ is calculated as follows:

$$
\begin{aligned}
& L_{m s a}=\frac{\mu_{o} l r}{g} \int_{0}^{2 \pi} W_{s a}^{2} d \gamma=\int_{0}^{2 \pi}\left(\frac{N_{s a}}{2} \cos (\gamma)\right)^{2} d \gamma \\
& =\frac{\mu_{o} l r}{g} N_{s a}^{2}\left(\frac{\pi}{4}\right)
\end{aligned}
$$

For the remaining phases $b$ and $c$, the same steps can be followed, where $L_{m s a}=L_{m s b}=L_{m s c}=L_{m s}$.

Also the mutual inductance of the stator coils $i$ and $j ; i, j \in\{a, b, c\}$ and $(i \neq j)$, is given by [19]:

$$
L_{\text {sisj }}=\frac{-L_{m s}}{2}
$$

The stator flux linkage due to the rotor current results in the mutual inductance between the stator coils and the rotor loops. The mutual inductance between the stator phase $j \in\{a, b, c\}$ and the rotor loop $i \epsilon$ $\left\{1,2, \ldots N_{r}\right\}$ can be calculated by substituting Equations (17) and (18) into (16), The final inductance formula will be as follows:

$$
L_{m(s j r i)}=\frac{\mu_{0} l r}{g} N_{s} \sin \left(\frac{\alpha_{r}}{2}\right) \cos \left(\begin{array}{l}
\left.\theta_{r}+(i-1) \alpha_{r}\right) \\
+\frac{\alpha_{r}}{2}-(j-1) \frac{2 \pi}{3}
\end{array}\right)
$$

From Equation (22), it can be noticed that the mutual inductance between stator and rotor depends on the relative position between stator and rotor.

\section{Rotor self and mutual inductances}

Rotor current contribute a flux linkage on the rotor loops, which can be represented by the loop inductance $L_{r p}$. Substituting Equation (18) into (16) can calculate the rotor Loop inductance. Its final formula will be as follows:

$$
L_{r p}=\frac{\mu_{o} l r}{g} \alpha_{r}\left(1-\frac{\alpha_{r}}{2 \pi}\right)
$$

In addition, the mutual inductance between two rotor loops $i$ and $j, i, j \in\left\{1,2, \ldots N_{r}\right\}$ and $(i \neq j)$ can be calculated by substituting (18) into (16) as explained in [19]. The final formula of the calculated inductance will be as follows.

$$
M_{r r}=-\frac{\mu_{o} l r}{g}\left(\frac{\alpha_{r}^{2}}{2 \pi}\right)
$$

The effect of the broken bars can be represented by simply eliminating the faulty bar elements, i.e. resistances and inductances. If the broken bar was the bar number $N_{r}$, then the fault will affect rotor current vector by removing the element $I_{r(\mathrm{Nr})}$. In addition, the fault will eliminate the $N_{r}$ row and column from both matrices $R_{r}$ and $L_{r}$ described in (8) and (12), respectively. The remaining $N_{r}-1$ branches in both equations should be re-evaluated. In addition, the effect of the fault on the mutual coupling matrix is represented by eliminating column number $N_{r}$ from $L_{m(s r)}$ matrix and the row number $N_{r}$ from $L_{m(r s)}$ matrix. Re-evaluation of the remaining $N_{r}-1$ rows and columns is required. The fault will also change the separation angle $\left(\alpha_{r}\right)$ with the adjacent bar to the faulty bar $N_{r}$, i.e. it will be doubled. Therefore, the WFA used in (18) will be changed in the case of faulty loop, as follows:

$$
W_{r(N r-1)}(\beta)=\left\{\begin{array}{l}
-\frac{\alpha_{r}}{\pi}, 0 \leq \theta_{r} \leq \theta_{(N r-1)} \\
1-\frac{\alpha_{r}}{\pi}, \theta_{(N r-1)} \leq \theta_{r} \leq 2 \pi
\end{array}\right.
$$

In general, for $n_{b}$ broken bars, the target parameters of $n_{b}$ faulty branches will be eliminated from the rotor resistance and inductance matrices. In addition, the $n_{b}$ columns and rows should be eliminated from the rotor-stator mutual coupling inductance matrix. The remaining $N_{r}-n_{b}$ branch elements should be re-evaluated to include the fault effect. The results of the rotor inductance matrix and rotor-stator mutual coupling inductance matrix will be as follows:

$$
\begin{aligned}
& L_{r p}=\frac{\mu_{o} l r}{g} \alpha_{r}\left(\left(n_{b}+1\right)-\left(n_{b}+1\right) \frac{\alpha_{r}}{\pi}\right) \\
& M_{r r}=-\frac{\mu_{o} l r}{g}\left(\frac{\alpha^{2}}{2 \pi}\right)\left(n_{b}+1\right) \\
& L_{m(s j i)}=\frac{\mu_{o} l r}{g} N_{s} \sin \left(\left(n_{b}+1\right) \frac{\alpha_{r}}{2}\right) \cos \left(\begin{array}{l}
\theta_{r}+\frac{2 i+n_{b}-1}{2} \alpha_{r} \\
-(j-1) \frac{2 \pi}{3}
\end{array}\right)
\end{aligned}
$$

\section{LSPMSM Simulation}

In this section, a simulation models are built based on MATLAB/ SIMULINK ${ }^{\circ}$ software and tested based on FEM method using JMAG software package.

\section{Proposed mathematical model simulation}

To investigate the effectiveness of the proposed mathematical equations, a SIMULINK model has been built to explore the behavior of the torque, speed and stator current of the 3-phase, $415 \mathrm{~V}, 4$-hp, 4-pole, $50 \mathrm{~Hz}$, LSPMSM. The motor parameters are given in Table 1. The simulation is intended to investigate the performance of the motor under different faulty conditions. This is in addition to investigating the ability of the motor to synchronize at different mechanical loading levels under both healthy and faulty conditions. SIMULINK ${ }^{\circ}$ model simulates the operation of LSPMSM in both transient and steady state, and return a clear indication regarding starting and steady state behavior of the motor's electromagnetic torque, stator phase current and rotor speed.

\section{FEM simulation using JMAG ${ }^{\circ}$ software}

In order to test the accuracy of the proposed mathematical model results and to conduct a compressive motor analysis, a new set of simulation results were obtained using commercial finite element based software, namely, JMAG. JMAG is a FEM simulation software package for electromagnetic design. It is based on converting conceptual design to a comprehensive analysis with a high accuracy in evaluating complex physical phenomena. The 2-D model of the LSPMSM is shown in Figure $1 \mathrm{a}$ and $1 \mathrm{~b}$ shows the FEM mesh used for analysis. 
Citation: Baradieh K, Al-Hamouz Z, Abido M (2018) ANN Based Broken Rotor Bar Fault Detection in LSPMS Motors. J Electr Electron Syst 7: 273. doi: 10.4172/2332-0796.1000273

\section{Simulation Results}

Simulation of a LSPMSM under healthy and broken bar conditions has been made using the proposed mathematical model and JMAG software. Figures 2-7 show a comparison of the stator phase current, torque and rotor speed of the healthy motor under no load and $1.5 \mathrm{NM}$ loading levels, respectively. The figures show that the time required to achieve synchronism is around $(0.3 \mathrm{sec}$.$) and (0.4 \mathrm{sec})$ at no load and 1.5 NM load, respectively. The same trend is happened at higher loading levels, where the transient time is increased as the loading level increased, until the motor lost its synchronism, Figure 8. However, Simulation results indicate a very good agreement between SIMULINK and $\mathrm{JMAG}^{\circ}$ models. The difference between the results yielded by two models arises due to the assumptions used in each one. For example, in the SIMULINK ${ }^{\circ}$ model, the current of the broken bar is assumed to be zero, while some current paths through laminations between adjacent bars are assumed to exist in the $\mathrm{JMAG}^{\circ}$ model. In addition, it is difficult to obtain the exact resistance value of the Aluminum conductors used in $\mathrm{JMAG}^{\circ}$ to represent the rotor bars in MATLAB'. These differences may also occur due to the mathematical operations, as the SIMULINK and $\mathrm{JMAG}^{\circ}$ simulations employ different solvers.

The effect of the broken bar conditions on the motor performance has been also investigated. Figures 9-11 show the stator current, torque and rotor speed for the case of three broken bars at $1.5 \mathrm{NM}$ loading level.

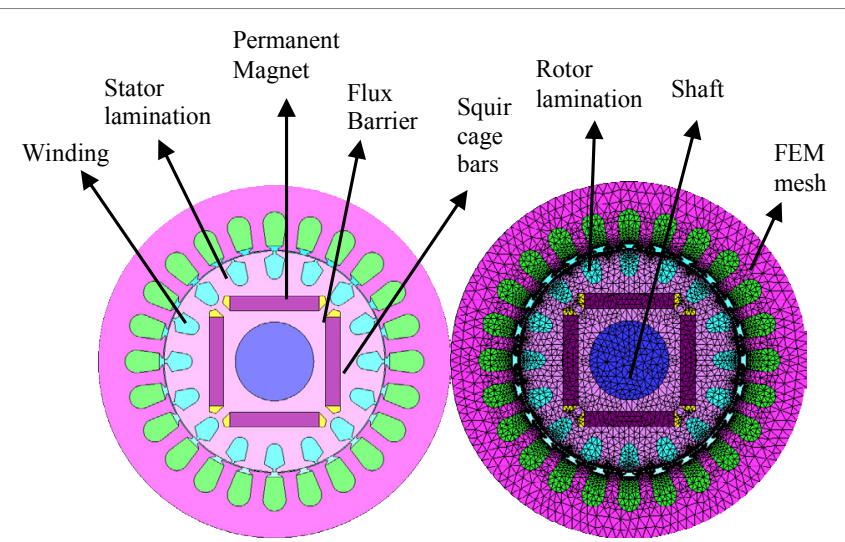

Figure 1: LSPMSM model using JMAG software.

a) 2D structure of the motor b) FEM mesh used for analysis

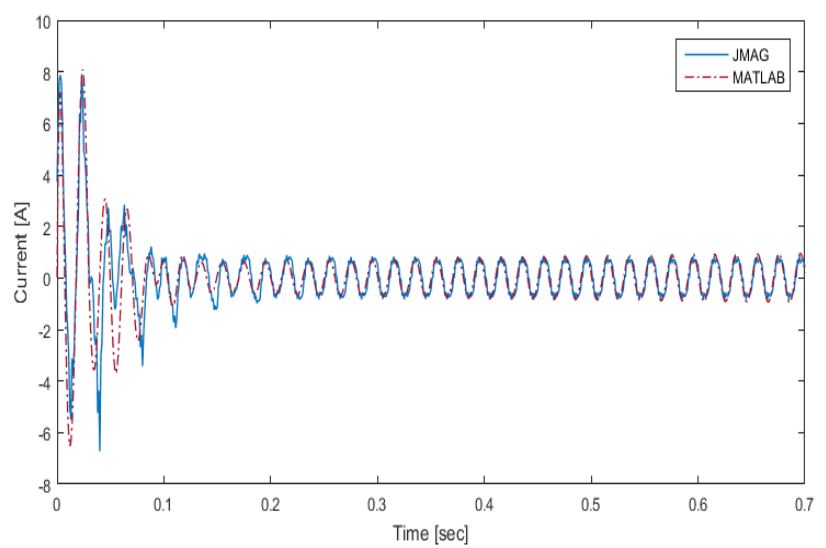

Figure 2: MATLAB and JMAG simulations of a healthy LSPMSM stator current at no load.

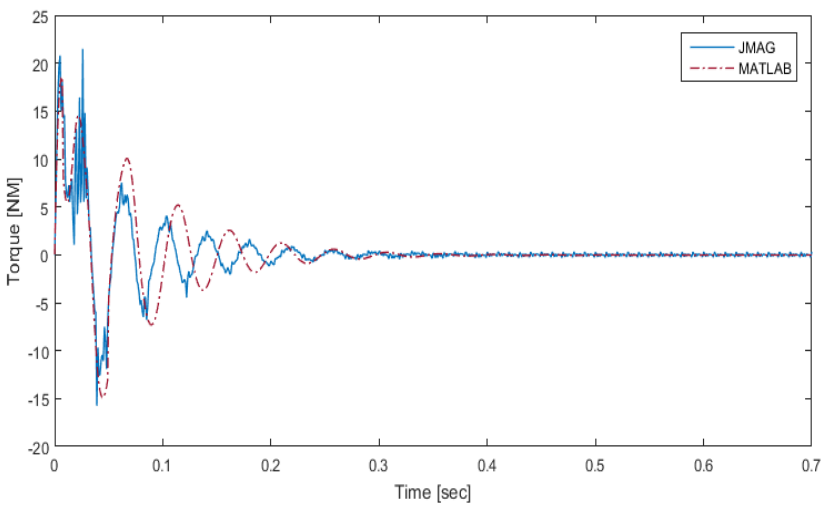

Figure 3: MATLAB and JMAG simulations of a healthy LSPMSM torque at no load.

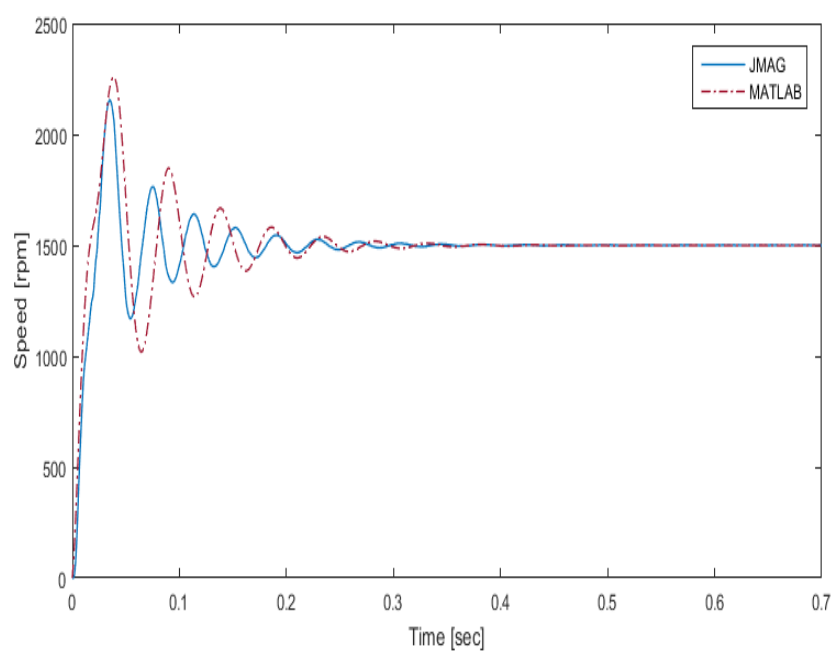

Figure 4: MATLAB and JMAG simulations of a healthy LSPMSM rotor speed at no load.

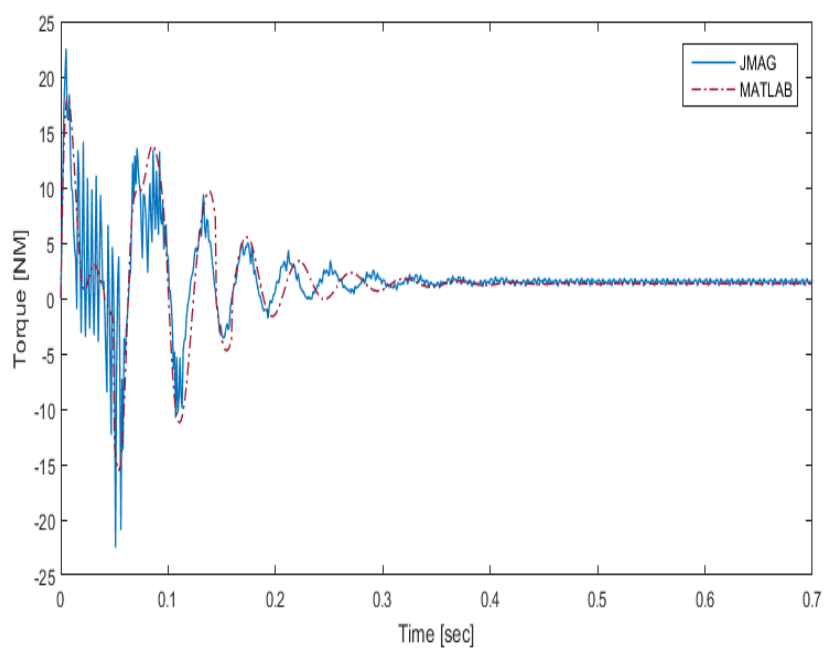

Figure 5: MATLAB and JMAG simulations of a healthy LSPMSM stator current at $1.5 \mathrm{NM}$ load. 
Citation: Baradieh K, Al-Hamouz Z, Abido M (2018) ANN Based Broken Rotor Bar Fault Detection in LSPMS Motors. J Electr Electron Syst 7: 273. doi: 10.4172/2332-0796.1000273

Page 6 of 14

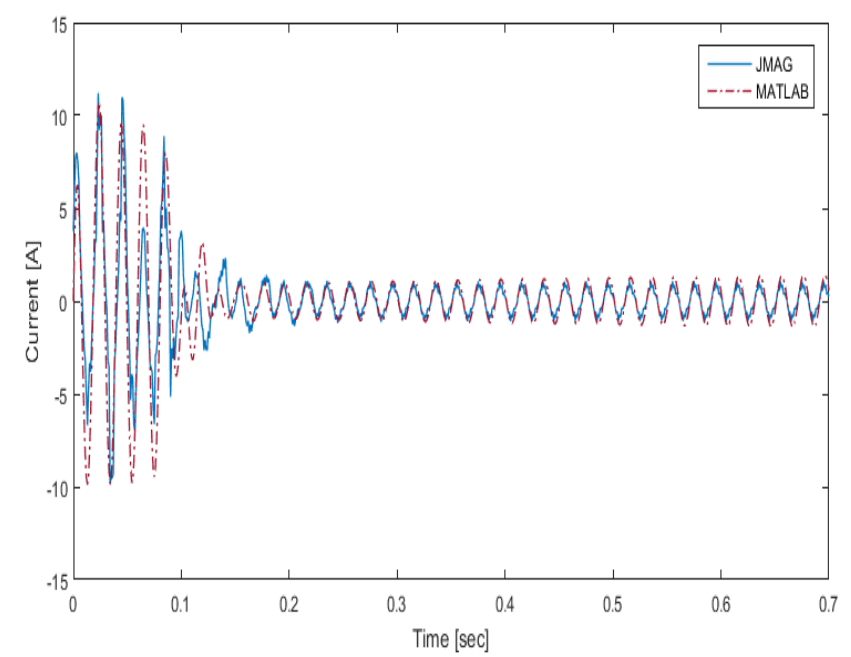

Figure 6: MATLAB and JMAG simulations of a healthy LSPMSM torque at $1.5 \mathrm{NM}$ load.

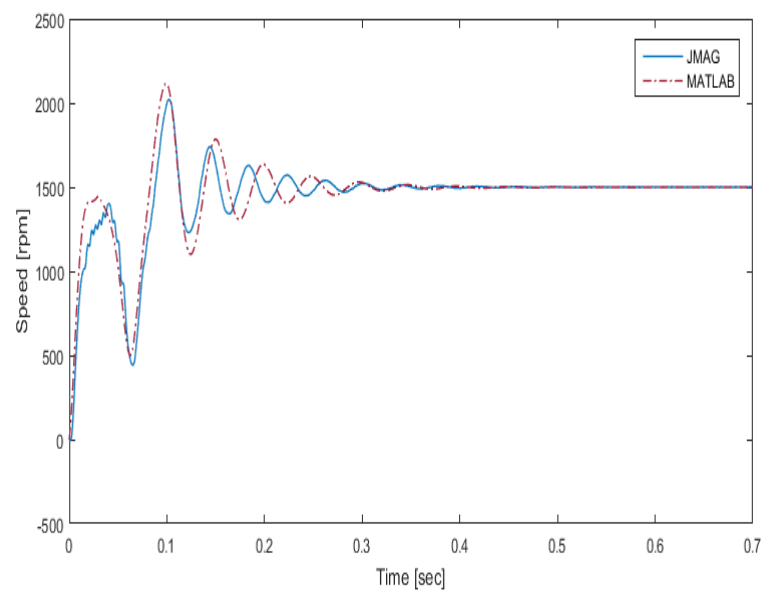

Figure 7: MATLAB ${ }^{\circledR}$ and $J M A G^{\circledR}$ simulations of a healthy LSPMSM rotor speed at $1.5 \mathrm{NM}$.

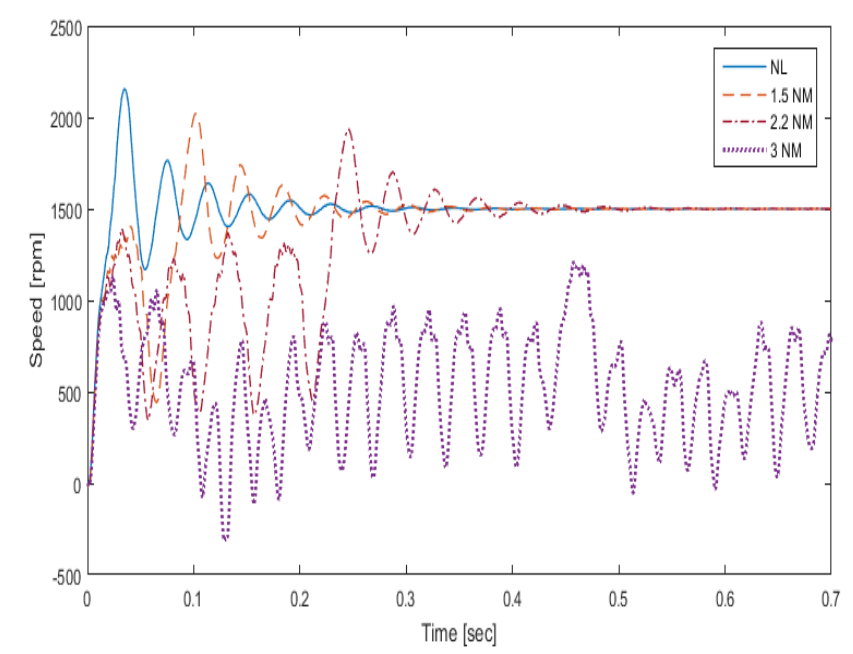

Figure 8: Simulation results of healthy LSPMSM rotor speed under different loading levels.

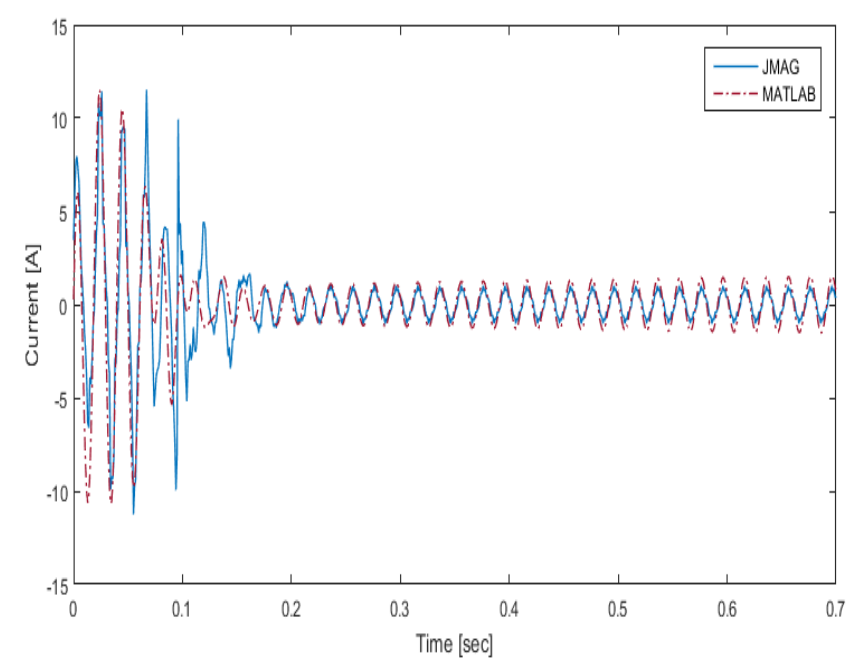

Figure 9: $M A T L A B^{\circledR}$ and $\mathrm{JMAG}^{\circledR}$ simulations of a faulty LSPMSM stator current at $1.5 \mathrm{NM}$ with 3 broken bars.

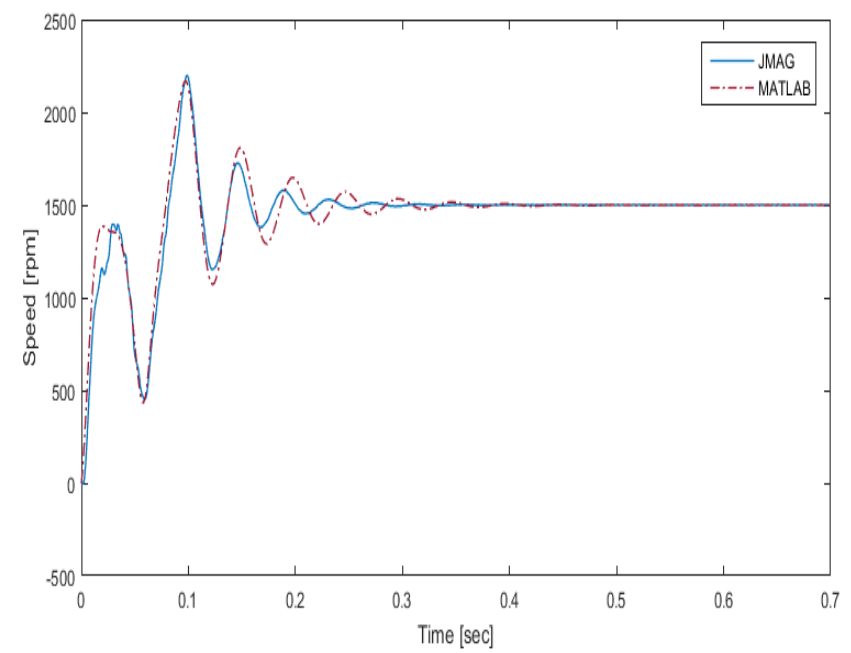

Figure 10: MATLAB ${ }^{\circledR}$ and $\mathrm{JMAG}^{\circledR}$ simulations of a faulty LSPMSM torque at 1.5 NM load with 3 broken bars.

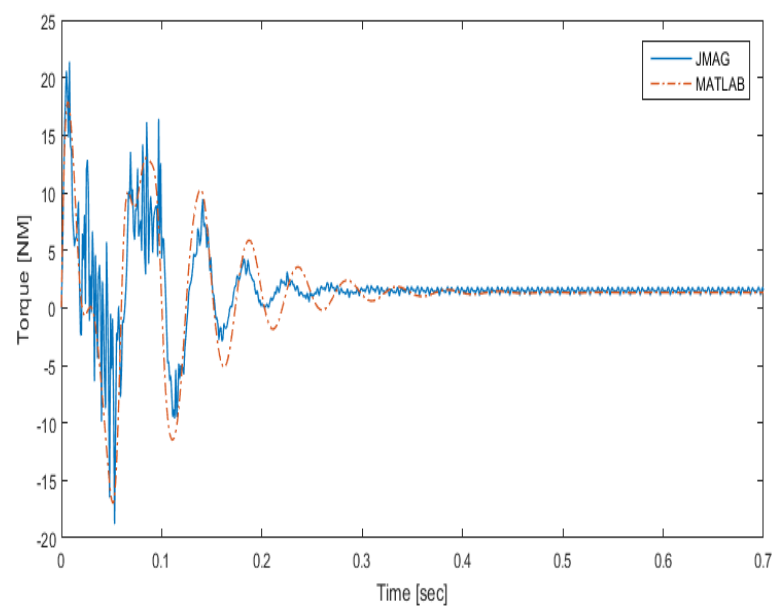

Figure 11: MATLAB ${ }^{\circledR}$ and $J M A G^{\circledR}$ simulations of a faulty LSPMSM rotor speed at $1.5 \mathrm{NM}$ load with 3 broken bars. 
In addition, Figure 12 shows the effect of varying the number of broken bars on the motor speed under 1.5 NM load. The results clearly show that, the synchronism is lost at five broken bars, which is approximately $1 / 3$ of the total number of rotor bars. This confirms with the findings reported in literature [20].

\section{ANN Based Broken Bar Fault Diagnosis}

Under normal operating conditions, the positive sequence of 3-phase balanced stator current produces a non-zero forward-rotating field in the air gap of the motor. This forward-rotating field induces currents in the rotor bars and end connectors. These induced rotor currents then produce forward and backward rotating fields in the air gap of the motor. For a symmetrical rotor, the resultant of the backward-rotating fields is zero, while the resultant of the forwardrotating field is non-zero. However, under any abnormal condition that destroys the symmetry of the rotor - such as broken bar fault- different scenario regarding the backward-rotating fields arises. In this case, the resultant of the backward-rotating fields is no longer zero. It is the ultimate identification of the effects of this non-zero backward-rotating field that forms the basis for most motor current signature analysis monitoring techniques. In other words, when a rotor bar is broken, no current flows in that bar. The resulting asymmetry in the rotor results in a non-zero backward-rotating field that rotates at a speed with respect to the rotor. This non-zero backward-rotating field induces harmonic currents in the stator winding which are superimposed on the stator winding currents [4]. Consequently, stator current signature is considered as a distinguishing primitive attribute or characteristic of the faulty motor under broken bar condition. Many methods can be applied on the stator current signature to obtain a milestone that highlights the differences between current signatures under different number of broken bars and at different loading levels. Such methods consist of statistical features such as Sum, Mean, Variance, RMS, Kurtosis, Skewness, Std., Median and RSSQ, and linear algebra based features such as singular value decomposition (SVD). However, since the broken bars fault affects the current signals over time, then it is preferable to deal with the stator phase current signature in time domain. In this paper, different features will be applied on the stator phase current to get the sub-optimal distinguishing milestones of the broken bars fault effect. Moreover, to achieve the best NN performance for diagnosing the broken bars fault, different $\mathrm{NN}$ algorithms as well as window sizes at different number of neurons were tested.

\section{Fault detection scheme}

The ANNs can adapt itself to learn different types of complicated linear and nonlinear functions. Therefore, it can learn a different type of motor faults which results in an accurate prediction of fault occurrence and its severity. This type of detection schemes is inexpensive and noninvasive. This paper aims at developing ANN based detection scheme which overcomes cost problems, complexity and applies different motor sizes. In conventional detection schemes, a detailed mathematical model is required and many features are needed to be extracted, which results in a costly instrument for measurement purposes [21]. However, the method used in this paper will use only the captured stator current data to extract the most important features. If these features are selected as the inputs to the ANN, then the detection of broken bar fault condition can be implemented. Besides, this scheme will be simple, economical, and reliable. The stator current is captured for a total time duration of $5 \mathrm{~s}$. Next, some important statistical parameters are calculated; this process is called feature extraction. For the selected features, the neural network is initialized with random weights to calculate the resultant errors. The calculated error will propagate through the backward cycle in order to update the weights and reduce the output MSE. This process is repeated until reaching a specified global minimum error. The neural network should be trained and tested carefully in the healthy and faulty states and under different loading levels. Figure 13 shows the main steps followed in the broken bar fault detection.

In the process of fault detection using ANNs, two problems are faced. First, the selection of neural network inputs, and specifying the network parameters. In the LSPMSM, the spectrum components of the broken bar fault in the line current are not fully specified. The authors in [22] specify the frequency components at which this fault can be detected. However, the authors stated that these frequencies are highly affected by any change in motor parameters, furthermore, the stator current spectrum contains not only the fault components, but also additional harmonics are usually presented such as slotting,

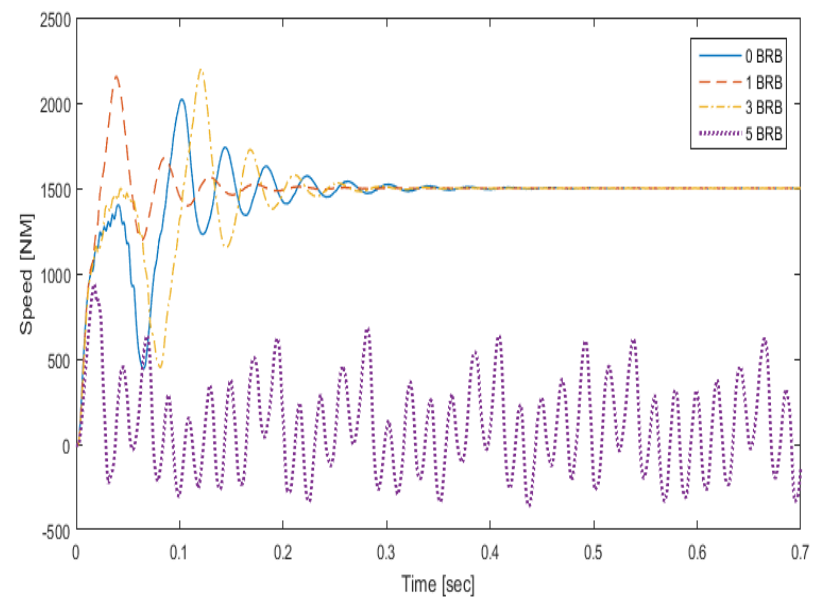

Figure 12: Rotor speed simulation results of a faulty LSPMSM with $0,1,3$ and 5 broken bars at 1.5 NM load.

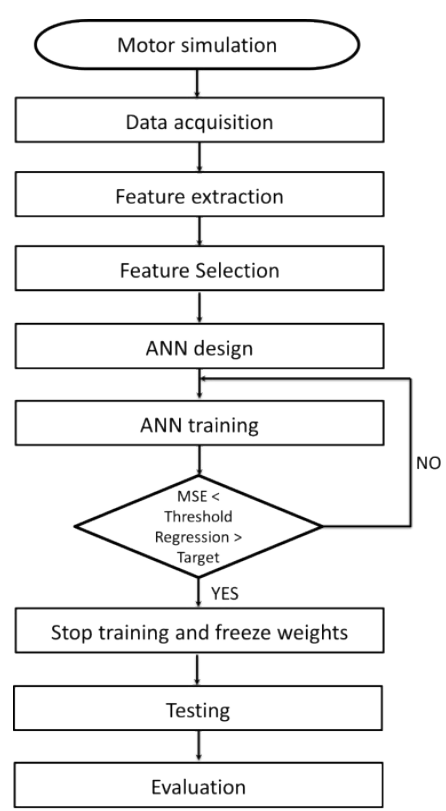

Figure 13: The main steps followed in the broken bar fault detection. 
supply voltage, and air gap space harmonics. In order to overcome these drawbacks, the feature extraction process will be based on the stator current in time domain.

Feature selection algorithms determine the most superior input variable which maximizes the performance of the detection process. The suitable predictor variable depends on the relationship between the input data. The selection process is not straightforward due to the large set of the available input variables as well as the Correlation between input variables, which creates redundancy. Modelers of ANNs realize that the input variable selection (IVS) algorithms should be utilized to maximize the network performance [23]. However, the desired input variables should be informative, i.e. with predictive ability, and less redundant. i.e. independent or dissimilar. In this paper, different statistical features will be examined as an input to the ANN. In addition, principal component analysis (PCA) [21] will be used as a filtering method to choose the most appropriate input variable that maximizes the ANN performance $[23,24]$.

\section{Principal Component Analysis (PCA)}

It is observed that there are many features need to be extracted, such features require significant computational efforts to calculate. Therefore, a method is needed to assist features selection and extraction. The concept of PCA can be used to select the most superior feature to detect the fault conditions. This method is analyzing the input data and extracting the most important information represented by a new set of orthogonal vectors called principal components (PCs). Each principal component (PC) represented by a vector of data. In mathematics, it's defined as a linear transformation of orthogonal vectors which map the data into a new space. Such that, the great variance from the data is the first dimension indicated as (F1), which is called the first PC. The second greatest variance located in the second dimension (F2) and so on $[21,25]$. For example, performing PCA to a stator current with a matrix dimension of 25 by 500 -this size gives the maximum accuracy as will be explained later- yields the eigenvalues and variability of projection as shown in Table 2 .

It is obvious that the first component carries $77.7 \%$ of the total

\begin{tabular}{|c|c|}
\hline Parameter & Value \\
\hline Rated Power $(\mathrm{W})$ & 750 \\
\hline Rated Voltage $(\mathrm{V})$ & 415 \\
\hline Stator phase resistance $(\Omega)$ & 19.15 \\
\hline Number of poles & 4 \\
\hline Frequency $(\mathrm{Hz})$ & 50 \\
\hline Air-gap length $(\mathrm{mm})$ & 0.3 \\
\hline Outer/inner stator diameter $(\mathrm{mm})$ & $120 / 75$ \\
\hline Number of stator slots & 24 \\
\hline Number of rotor bars & 16 \\
\hline Axial length of stator core $(\mathrm{mm})$ & 75 \\
\hline Number of turns per slot & 139 \\
\hline Height of stator yoke $(\mathrm{mm})$ & 45 \\
\hline Height of stator/rotor slots $(\mathrm{mm})$ & $13 / 9.5$ \\
\hline Remanent of magnet $(\mathrm{T})$ & 1.02 \\
\hline
\end{tabular}

Table 1: LSPMSM electromagnetic design.

\begin{tabular}{|c|c|c|c|c|}
\hline & F1 & F2 & F3 & F4 \\
\hline Eigenvalue & 8.554 & 1.262 & 0.753 & 0.320 \\
\hline Variability (\%) & 77.765 & 11.474 & 6.842 & 2.907 \\
\hline Cumulative \% & 77.765 & 89.239 & 96.081 & 98.988 \\
\hline
\end{tabular}

Table 2: Eigen values and variability of the stator current projection. information in the input signal with the largest eigenvalue of 8.5. The second axis carries only $11.4 \%$ of the total projection data. Both axes implement $89.24 \%$ of the total data as shown in Figure 14. The variability of data projection on the third and fourth axes is small with $6.8 \%$ for the third axis and $2.9 \%$ for the fourth axis, respectively. It can be concluded that the first PC can be used as the input variable to the ANN with $77.7 \%$ of the variability.

\section{Statistical variables}

As discussed before, a common selection method of variables is the filter method. This selection method process is the one before ANN training to choose the best input variable which maximize the network performance. This method is based on measuring the relevance between individual variables in a group of inputs. This function is performed using search algorithm such as the correlation. The selection criteria of this method is based on the maximum relevance (MR) which selects the most informative variables and the minimum redundancy $(\mathrm{mR})$ which selects variables with unique features [23]. Using a collection set of dimensional and non-dimensional statistical features to generate the input variable, the correlation-based filter method can be utilized. For the input row data $\mathrm{X}$ (stator current), the selected features to be calculated are chose to be as follows:

$$
\begin{aligned}
& \text { Sum }=X_{\text {sum }}=\sum X_{i} \\
& \text { Mean }=X_{\text {mean }}=\frac{\sum X_{i}}{N} \\
& \text { RMS }=X_{R M S}=\sqrt{\frac{\sum X_{i}^{2}}{N}} \\
& \text { RSSQ }=X_{R S S Q}=\sqrt{\sum\left|X_{i}^{2}\right|} \\
& \text { Std }=X_{\text {std. }}=\sqrt{\sum_{i=1}^{N} \frac{\left(X_{i}-X_{\text {mean }}\right)^{2}}{N}} \\
& \text { Variance }=X_{v}=\frac{\sum\left|X_{i}-X_{\text {mean }}\right|^{2}}{N-1} \\
& \text { Kurtosis }=X_{k}=\frac{1}{N} \frac{\sum\left(X_{i}-X_{\text {mean }}\right)^{4}}{X_{\text {std. }}}
\end{aligned}
$$

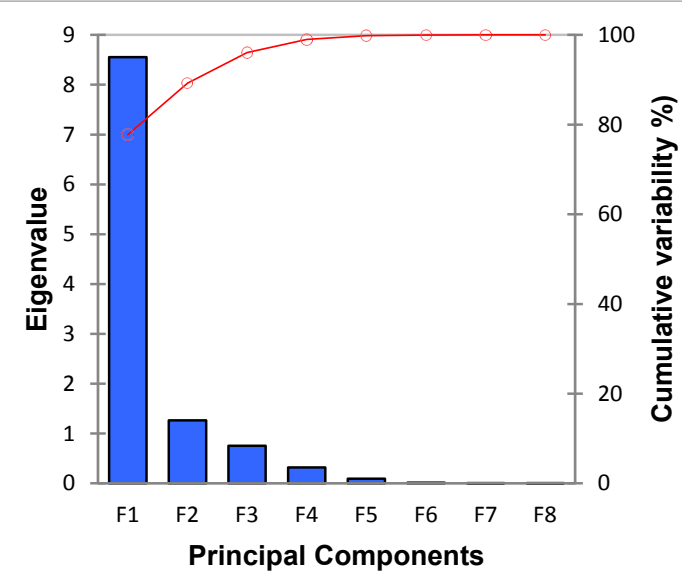

Figure 14: Stator Current principal component. 


$$
\begin{aligned}
& \text { Skewness }=X_{s k}=\frac{3\left(X_{\text {mean }}-X_{\text {median }}\right)}{X_{\text {std }} .} \\
& \text { Median }=X_{\text {median }}=\frac{\left(\frac{N}{2}\right)^{\text {th }} \text { term }+\left(\frac{N}{2}+1\right)^{t h} \text { term }}{2}
\end{aligned}
$$

Where $\mathrm{N}$ is the number of samples.

These features are calculated under different operating conditions, which include a combination of different number of broken bars and loading levels. The calculation of the correlation is conducted using Pearson method. The obtained correlation matrix is depicted in Table 3.

Based on the PCA assist, it can be noted that the minimum redundancy criteria suggest the SVD method as the qualified input to the ANN with a minimum correlation to the other variables. Furthermore, the PCA can be used to assist the process of selecting the inputs. Figure 15 presents the correlation circle for the input variables projected in the first two PCs based on the previously used statistical features. It is obvious that RMS, variance, Median, Mean, Sum, Kurtosis, Skewness, and RSSQ are strongly correlated to each other and redundant. Some unique features are carried by the SVD feature. In conclusion, the IVS method and PCA suggest using SVD of the stator current as the input to the ANN for training.

In $\mathrm{NN}$ training, the weights are chosen randomly before commencing the training process. Supervised training which is requires providing the network with the desired outputs before and during the training process is the commonly used training method, therefore it is utilized in this paper. The network compares the hidden layer's outputs with the desired outputs and adjusts the weights through the feedback algorithms known as "backward error propagation". The system terminates at the desired accuracy point. This process is known as "self-organization" or "self-adaption" [26].

\section{Combined ANN -SVD Method For Broken Bar Diagnosis}

\section{Applying the SVD theorem on the LSPMSM stator current}

In order to apply the SVD theorem in broken bar fault diagnostics, current signatures were collected by simulating the motor described in Table 1 under different numbers of broken bars and at different loading levels for $5 \mathrm{~s}$ of simulation time. Each current signature was arranged in one row of the matrix $Y$. Therefore, the stator current matrix $Y$ contains the current signatures obtained through motor simulation under 11 different loads and 3 different numbers of broken bars, which will be used in training process. Hence, the current matrix $Y$ will contain all probabilities of simulation cases, which are represented in 33 current rows, where each row pertains to a stator current vector with 12500 points at fixed step-size with fundamental sampling time (1/2500). The load vector (in per unit) and the broken bars vector can be represented as follows:

$$
\begin{aligned}
& L=\left[\begin{array}{lllllllllll}
0 & 0.1 & 0.2 & 0.3 & 0.4 & 0.5 & 0.6 & 0.7 & 0.8 & 0.9 & 1
\end{array}\right] \\
& B R B=\left[\begin{array}{lll}
0 & 2 & 4
\end{array}\right]
\end{aligned}
$$

where $\mathrm{L}$ denotes the loading level vector in pu and BRB is the broken bars vector. The entire current matrix $\mathrm{Y}$ will be of size $33 \times$ 12,500. Each current row of the matrix $\mathrm{Y}$ is divided into segments to obtain a distinguishing attribute from each segment. Tests were performed with different numbers of windows and different number of points per window to obtain the best window size that will pertain the sub-optimal NN performance, as will be shown in the next sub-section. The findings indicated that; five current segments with 2,500 data points in each represent the sub-optimal current segmentation that will yield the best $\mathrm{NN}$ performance. These segments were rearranged in separate matrices $x i, i \in\{1,2, \ldots, 33\}$, where each matrix represents one row of the whole current matrix $\mathrm{Y}$ and consists of 5 rows and 2,500 columns. Singular value decomposition approach was applied on each matrix with the help of MATLAB ${ }^{\circ}$ SVD toolbox. This process returned SVD matrix with 33 vectors of singular values, whereby each vector represents the eigenvector for each simulation case of the previously described 33 cases. The formulated SVD vectors will be used later as an input to the multi-layer neural network. Error! Reference source not found. Figure 16 illustrates the previously described steps that have been followed to formulate the NN input data.

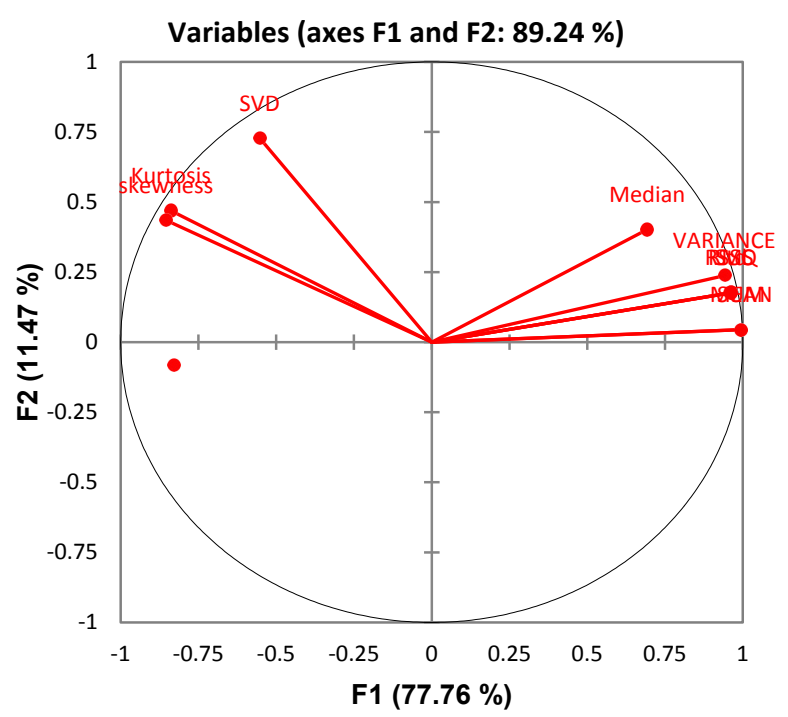

Figure 15: Correlation circle of the input variables.

\begin{tabular}{|c|c|c|c|c|c|c|c|c|c|c|}
\hline Variables & SVD & MEAN & SUM & VARIANCE & RMS & Kurtosis & skewness & Std & Median & RSSQ \\
\hline SVD & 1 & $\mathbf{- 0 . 7 1 7}$ & $\mathbf{- 0 . 6 1 7}$ & $\mathbf{- 0 . 8 7 0}$ & $\mathbf{- 0 . 4 1 7}$ & $\mathbf{- 0 . 7 1 6}$ & $\mathbf{- 0 . 6 9 7}$ & $\mathbf{- 0 . 4 1 7}$ & $\mathbf{- 0 . 1 6 2}$ & $\mathbf{- 0 . 7 1 7}$ \\
\hline MEAN & $\mathbf{- 0 . 7 1 7}$ & 1 & 1.000 & 0.967 & 0.984 & 0.802 & 0.824 & 0.984 & 0.656 & 0.984 \\
\hline SUM & $\mathbf{- 0 . 6 1 7}$ & 1.000 & 1 & 0.967 & 0.984 & 0.802 & 0.824 & 0.984 & 0.656 & 0.984 \\
\hline VARIANCE & $\mathbf{- 0 . 8 7 0}$ & 0.967 & 0.967 & 1 & 0.992 & 0.643 & 0.663 & 0.992 & 0.632 & 0.992 \\
\hline RMS & $\mathbf{- 0 . 4 1 7}$ & 0.984 & 0.984 & 0.992 & 1 & 0.689 & 0.726 & 1.000 & 0.635 & 1.000 \\
\hline Kurtosis & $\mathbf{- 0 . 7 1 6}$ & 0.802 & 0.802 & 0.643 & 0.689 & 1 & 0.970 & 0.689 & 0.422 & $-\mathbf{0 . 6 8 9}$ \\
\hline skewness & $\mathbf{- 0 . 6 9 7}$ & 0.824 & 0.824 & 0.663 & 0.726 & 0.970 & 1 & 0.726 & 0.437 & 0.726 \\
\hline Std. & $\mathbf{- 0 . 4 1 7}$ & 0.984 & 0.984 & 0.992 & 1.000 & 0.689 & 0.726 & 1 & 0.635 & 1.000 \\
\hline Median & $\mathbf{- 0 . 1 6 2}$ & 0.656 & 0.656 & 0.632 & 0.635 & 0.422 & 0.437 & 0.635 & 1 \\
\hline RSSQ & $\mathbf{- 0 . 7 1 7}$ & 0.984 & 0.984 & 0.992 & 1.000 & $\mathbf{- 0 . 6 8 9}$ & 0.726 & 1.000 & 0.635 & 1 \\
\hline
\end{tabular}

Table 3: Correlation matrix of the selected input variables. 


\section{Using the formulated SVD matrix in MFNN training}

As previously mentioned, MFNN was used to diagnose and monitor the occurrence and the size of the broken bars fault in LSPMSM. The inputs to the network are the singular vectors of the stator current matrix and the outputs are the number of broken bars. In order to design and test the neural network, the extracted SVD matrix of 33 columns, discussed in the preceding subsection, was forwarded to the neural network. Using MATLAB neural network toolbox, the MFNN design requires determining the input training matrix, the target training vector (desired outputs) and the number of neurons in the hidden layer [27].

During training process, three kinds of samples can be used for validation and testing the input data in the MATLAB neural network toolbox. Training samples, which were presented to the network during the training, are used to adjust the network per its error value. Validation samples are used to measure the network generalization and to halt training when generalization stops improving. In addition, testing samples, which have no effect on the training process but provide an independent measure of the network performance during and after training, are also utilized. However, in the testing presented in this section, 70\% (23 samples) of the 33

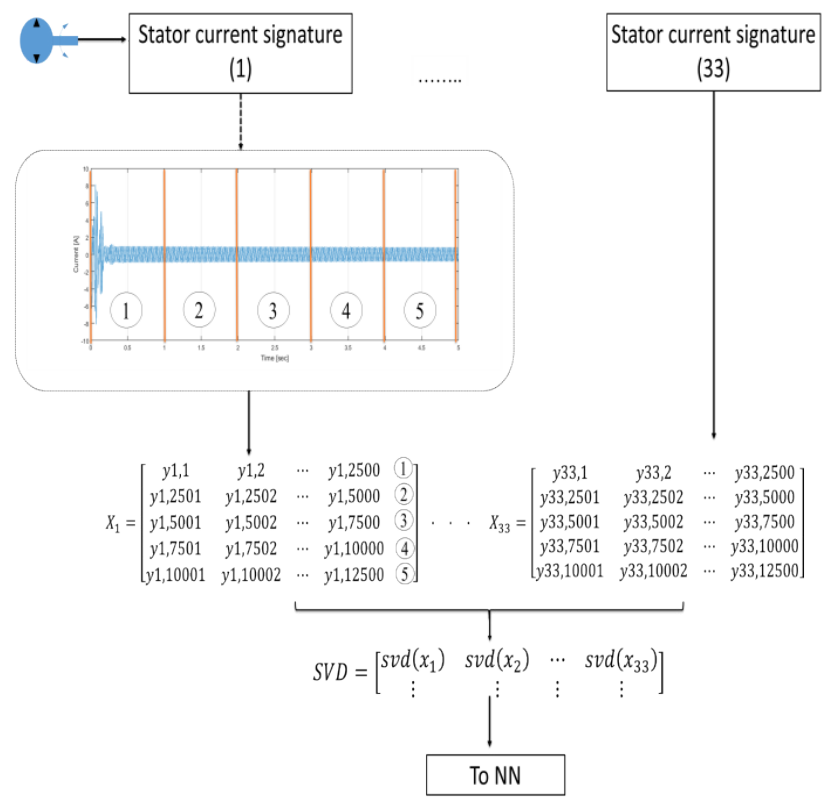

Figure 16: Methodology of formulating NN input data.

\begin{tabular}{|c|c|c|}
\hline No. & Parameter & Value \\
\hline 1 & Input training & SVD vectors [8x33]. \\
\hline 2 & Target training & {$\left[\begin{array}{l}2 \\
2\end{array}\right]$} \\
\hline 3 & No. of hidden neurons & 11 \\
\hline 4 & No. of Epochs & 1000 \\
\hline 5 & Learning rate & 0.018 \\
\hline 6 & Training algorithm & Bayesian Regularization algorithm \\
\hline
\end{tabular}

Table 4: ANN learning parameters.

\begin{tabular}{|c|c|c|c|}
\hline Parameter & No. of samples & MSE & $\mathbf{R}$ \\
\hline Training & 23 & $4.785 \times 10^{-15}$ & 1 \\
\hline Testing & 5 & $4.584 \times 10^{-3}$ & 0.99266 \\
\hline
\end{tabular}

Table 5: MSE and regression of the trained NN. input samples were used for training, $15 \%$ (5 samples) were used for validation and 15\% (5 samples) were used for testing. The next step is to determine the network architecture by setting the number of neurons in the hidden layer. The sub-optimal number of neurons which maximized the network performance were 11 neurons as shown in the next section. In addition, Bayesian Regularization training algorithm was used because of its beneficial properties, while the parameters used for ANN training are summarized in Table 4.

In order to measure the accuracy of the built network during the trial and error step, two measurement tools were used, one of which is Mean Square Error (MSE); that measures the average squared difference between outputs and targets, where lower values are better and zero denotes absence of errors. In addition, Regression (R) was used to measure the correlation between outputs and targets. R-value of 1 means a close relationship and 0 indicates no or random relationship. The MSE and regression of the trained neural network are presented in Table 5 .

\begin{tabular}{|c|c|c|c|c|}
\hline $\begin{array}{l}\text { Case } \\
\text { No. }\end{array}$ & $\begin{array}{l}\text { (Window size, } \\
\text { No. of points/ } \\
\text { window) }\end{array}$ & $\begin{array}{c}\text { No. of } \\
\text { neurons }\end{array}$ & $\begin{array}{l}\text { Testing samples } \\
\text { (MSE) }\end{array}$ & $\begin{array}{c}\text { Testing samples } \\
\text { (Regression) }\end{array}$ \\
\hline 1 & \multirow{5}{*}{$(5,2500)$} & 5 & 0.0017577 & 0.984566 \\
\hline 2 & & 9 & 0.530589 & 0.967486 \\
\hline 3 & & 11 & 0.00058467 & 0.99266 \\
\hline 4 & & 12 & 0.846713 & 0.900062 \\
\hline 5 & & 15 & 0.600628 & 0.926761 \\
\hline 6 & \multirow{5}{*}{$(10,1250)$} & 5 & 1.40555 & 0.755602 \\
\hline 7 & & 9 & 0.113877 & 0.992901 \\
\hline 8 & & 11 & 0.842064 & 0.854919 \\
\hline 9 & & 12 & 0.243494 & 0.982903 \\
\hline 10 & & 15 & 0.827255 & 0.850975 \\
\hline 11 & \multirow{5}{*}{$(20,625)$} & 5 & 0.572729 & 0.968345 \\
\hline 12 & & 9 & 0.493744 & 0.953185 \\
\hline 13 & & 11 & 0.964008 & 0.866366 \\
\hline 14 & & 12 & 0.532925 & 0.928532 \\
\hline 15 & & 15 & 0.719404 & 0.896085 \\
\hline 16 & \multirow{5}{*}{$(25,500)$} & 5 & 0.738655 & 0.894466 \\
\hline 17 & & 9 & 0.977169 & 0.751925 \\
\hline 18 & & 11 & 0.390965 & 0.992607 \\
\hline 19 & & 12 & 0.79253 & 0.822196 \\
\hline 20 & & 15 & 0.963993 & 0.828237 \\
\hline 21 & \multirow{5}{*}{$(50,250)$} & 5 & 0.320680 & 0.959092 \\
\hline 22 & & 9 & 0.643199 & 0.596024 \\
\hline 23 & & 11 & 1.30952 & 0.978504 \\
\hline 24 & & 12 & 0.702070 & 0.922750 \\
\hline 25 & & 15 & 0.540342 & 0.900495 \\
\hline 26 & \multirow{5}{*}{$(100,125)$} & 5 & 4.37762 & 0.299078 \\
\hline 27 & & 9 & 7.24313 & -0.231649 \\
\hline 28 & & 11 & 6.12528 & 0.795691 \\
\hline 29 & & 12 & 3.62068 & 0.564662 \\
\hline 30 & & 15 & 1.62543 & 0.721844 \\
\hline
\end{tabular}

Table 6: NN training using different window sizes and No. of neurons. 
Citation: Baradieh K, Al-Hamouz Z, Abido M (2018) ANN Based Broken Rotor Bar Fault Detection in LSPMS Motors. J Electr Electron Syst 7: 273. doi: 10.4172/2332-0796.1000273

Page 11 of 14

\section{The Effect of Number of Neurons, Window Size and Training Algorithm on the NN Performance}

In order to achieve the best NN performance for diagnosing the broken bars fault, different number of neurons and window sizes as well as training algorithms were tested and clarified in the next subsections.

The effect of the window size and number of neurons on the NN performance

The stator current window size affects the network accuracy. Table 6 shows different trials aiming at obtaining the sub-optimal feature at different window sizes and with different numbers of neurons by fixing the training algorithm (Bayesian algorithm). The best network accuracy was obtained at 25 windows for each stator current with 500 data points for each, and with 11 hidden layer neurons using the SVD feature.

\begin{tabular}{|c|c|c|c|c|}
\hline $\begin{array}{l}\text { Case } \\
\text { No. }\end{array}$ & $\begin{array}{l}\text { Used } \\
\text { Algorithm }\end{array}$ & $\begin{array}{c}\text { No. of } \\
\text { neurons }\end{array}$ & $\begin{array}{l}\text { Testing samples } \\
\text { (MSE) }\end{array}$ & $\begin{array}{c}\text { Testing samples } \\
\text { (Regression) }\end{array}$ \\
\hline 1 & \multirow{12}{*}{$\begin{array}{l}\text { Levenberg- } \\
\text { Marquardt }\end{array}$} & 2 & 2.09785 & 0.626813 \\
\hline 2 & & 5 & 1.6266 & 0.976664 \\
\hline 3 & & 7 & 0.893722 & 0.846778 \\
\hline 4 & & 9 & 0.75342 & 0.84581 \\
\hline 5 & & 10 & 0.427154 & 0.958723 \\
\hline 6 & & 11 & 0.104874 & 0.98823 \\
\hline 7 & & 12 & 1.28624 & 0.792055 \\
\hline 8 & & 15 & 0.658078 & 0.903213 \\
\hline 9 & & 17 & 3.84497 & -0.167069 \\
\hline 10 & & 20 & 0.104874 & 0.98823 \\
\hline 11 & & 25 & 1.87696 & 0.699264 \\
\hline 12 & & 30 & 0.654845 & 0.910816 \\
\hline 13 & \multirow{12}{*}{$\begin{array}{c}\text { Bayesian } \\
\text { Regularization }\end{array}$} & 2 & 1.73211 & 0.852492 \\
\hline 14 & & 5 & 1.539434 & 0.818052 \\
\hline 15 & & 7 & 0.729192 & 0.925733 \\
\hline 16 & & 9 & 0.00732756 & 0.983494 \\
\hline 17 & & 10 & 0.0064469 & 0.978297 \\
\hline 18 & & 11 & $4.58467 x^{3}$ & 0.99266 \\
\hline 19 & & 12 & 0.124710 & 0.988456 \\
\hline 20 & & 15 & 1.69543 & 0.434623 \\
\hline 21 & & 17 & 1.34332 & 0.935624 \\
\hline 22 & & 20 & 0.748392 & 0.858596 \\
\hline 23 & & 25 & 0.853030 & 0.879769 \\
\hline 24 & & 30 & 3.64849 & 0.591054 \\
\hline 25 & \multirow{12}{*}{$\begin{array}{c}\text { Scaled } \\
\text { conjugate } \\
\text { Gradient }\end{array}$} & 2 & 0.709130 & 0.915576 \\
\hline 26 & & 5 & 0.302373 & 0.971618 \\
\hline 27 & & 7 & 2.68453 & 0.521451 \\
\hline 28 & & 9 & 0.416194 & 0.984492 \\
\hline 29 & & 10 & 0.340863 & 0.970376 \\
\hline 30 & & 11 & 0.200330 & 0.976306 \\
\hline 31 & & 12 & 0.635342 & 0.957161 \\
\hline 32 & & 15 & 2.79162 & 0.771812 \\
\hline 33 & & 17 & 0.261919 & 0.991968 \\
\hline 34 & & 20 & 0.363748 & 0.974512 \\
\hline 35 & & 25 & 0.851280 & 0.947751 \\
\hline 36 & & 30 & 0.285872 & 0.893380 \\
\hline
\end{tabular}

Table 7: NN training using different algorithms and number of Neurons.

\section{The effect of the training algorithm and number of neurons}

MATLAB NN toolbox presents three types of training algorithms: Levenberg-Marquardt, Bayesian Regularization and Scaled Conjugate Gradient. Levenberg-Marquardt algorithm typically requires more memory but less time. Training automatically stops when generalization stops improving, as indicated by an increase in the mean square error of the validation samples. Bayesian Regularization typically requires more time, but can result in good generalization for difficult, small or noisy datasets. Training stops according to adaptive weight minimization (regularization). The third algorithm is the Scaled Conjugate Gradient algorithm, which requires less memory. Training automatically stops when generalization stops improving, as indicated by an increase in the mean square error of the validation samples. Table 7 shows the test samples MSE and regression obtained using the three algorithms for $\mathrm{NN}$ training with different numbers of neurons and at fixed window size. It is evident that the $\mathrm{NN}$ exhibits the best performance when using Bayesian algorithm with 11 neurons. Therefore, Bayesian algorithm will be used for NN training with 11 neurons.

\begin{tabular}{|c|c|c|c|c|c|}
\hline No. & $\begin{array}{l}\text { Loading } \\
\text { level (pu) }\end{array}$ & $\begin{array}{c}\text { Detected No. } \\
\text { of BRB }\end{array}$ & $\begin{array}{c}\text { Actual No. } \\
\text { of BRB }\end{array}$ & Status & \%NMSE \\
\hline 1 & \multirow{3}{*}{0} & 0.71995 & 1 & Correct & 0.464319938 \\
\hline 2 & & 2.7399 & 3 & Correct & 0.964065028 \\
\hline 3 & & 5.0395 & 5 & Correct & 0.593125662 \\
\hline 4 & \multirow{3}{*}{0.1} & 1.2208 & 1 & Correct & 0.0556476 \\
\hline 5 & & 2.9327 & 3 & Correct & 0.39533232 \\
\hline 6 & & 5.3139 & 5 & Correct & 0.07160035 \\
\hline 7 & \multirow{3}{*}{0.2} & 0.87234 & 1 & Correct & 0.161851479 \\
\hline 8 & & 2.9546 & 3 & Correct & 0.346502569 \\
\hline 9 & & 5.4590 & 5 & Correct & $3.356 \times 10^{-06}$ \\
\hline 10 & \multirow{3}{*}{0.3} & 0.0029834 & 1 & Incorrect & 3.784421539 \\
\hline 11 & & 2.8418 & 3 & Correct & 0.632403628 \\
\hline 12 & & 5.2899 & 5 & Correct & 0.097056213 \\
\hline 13 & \multirow{3}{*}{0.4} & 0.56499 & 1 & Correct & 0.931649224 \\
\hline 14 & & 3.1973 & 3 & Correct & 0.020776107 \\
\hline 15 & & 4.7598 & 5 & Correct & 1.644594856 \\
\hline 16 & \multirow{3}{*}{0.5} & 0.92849 & 1 & Correct & 0.089681601 \\
\hline 17 & & 3.0091 & 3 & Correct & 0.238952656 \\
\hline 18 & & 4.8877 & 5 & Correct & 1.098657201 \\
\hline 19 & \multirow{3}{*}{0.6} & 0.74805 & 1 & Correct & 0.396830772 \\
\hline 20 & & 3.0635 & 3 & Correct & 0.151472078 \\
\hline 21 & & 4.7788 & 5 & Correct & 1.556553288 \\
\hline 22 & \multirow{3}{*}{0.7} & 0.73143 & 1 & Correct & 0.43610784 \\
\hline 23 & & 3.0838 & 3 & Correct & 0.123914315 \\
\hline 24 & & 4.7163 & 5 & Correct & 1.85528348 \\
\hline 25 & \multirow{3}{*}{0.8} & 0.69073 & 1 & Correct & 0.540117313 \\
\hline 26 & & 3.1322 & 3 & Correct & 0.069363738 \\
\hline 27 & & 4.5783 & 5 & Correct & 2.60769261 \\
\hline 28 & \multirow{3}{*}{0.9} & 0.66423 & 1 & Correct & 0.613811982 \\
\hline 29 & & 3.1864 & 3 & Correct & 0.026929652 \\
\hline 30 & & 4.5354 & 5 & Correct & 2.867625891 \\
\hline 31 & \multirow{3}{*}{1} & 0.54143 & 1 & Correct & 1.016809983 \\
\hline 32 & & 3.2751 & 3 & Correct & 2.71706E-06 \\
\hline 33 & & 4.5193 & 5 & Correct & 2.968362953 \\
\hline
\end{tabular}

Statistics:

$\%$ NMSE $=0.4064 \%$

No. Wrongs $=1$

No. Corrects $=32$

$\%$ Success $=(65 / 66)^{\star} 100 \%=96.97 \%$

Table 8: NN testing - First test (All input loads are trained and all No. of input broken bars are NOT trained). 
Citation: Baradieh K, Al-Hamouz Z, Abido M (2018) ANN Based Broken Rotor Bar Fault Detection in LSPMS Motors. J Electr Electron Syst 7: 273. doi: 10.4172/2332-0796.1000273

Page 12 of 14

\begin{tabular}{|c|c|c|c|c|c|}
\hline No. & $\begin{array}{l}\text { Loading } \\
\text { level (pu) }\end{array}$ & $\begin{array}{l}\text { Detected } \\
\text { No. of BRB }\end{array}$ & $\begin{array}{l}\text { Actual No. } \\
\text { of BRB }\end{array}$ & Status & \%NMSE \\
\hline 1 & \multirow{3}{*}{0} & 0.71995 & 1 & Correct & 0.464319938 \\
\hline 2 & & 2.7399 & 3 & Correct & 0.964065028 \\
\hline 3 & & 5.0395 & 5 & Correct & 0.593125662 \\
\hline 4 & \multirow{3}{*}{0.1} & 1.2208 & 1 & Correct & 0.0556476 \\
\hline 5 & & 2.9327 & 3 & Correct & 0.39533232 \\
\hline 6 & & 5.3139 & 5 & Correct & 0.07160035 \\
\hline 7 & \multirow{3}{*}{0.2} & 0.87234 & 1 & Correct & 0.161851479 \\
\hline 8 & & 2.9546 & 3 & Correct & 0.346502569 \\
\hline 9 & & 5.4590 & 5 & Correct & $3.356 \times 10^{-06}$ \\
\hline 10 & \multirow{3}{*}{0.3} & 0.0029834 & 1 & Incorrect & 3.784421539 \\
\hline 11 & & 2.8418 & 3 & Correct & 0.632403628 \\
\hline 12 & & 5.2899 & 5 & Correct & 0.097056213 \\
\hline 13 & \multirow{3}{*}{0.4} & 0.56499 & 1 & Correct & 0.931649224 \\
\hline 14 & & 3.1973 & 3 & Correct & 0.020776107 \\
\hline 15 & & 4.7598 & 5 & Correct & 1.644594856 \\
\hline 16 & \multirow{3}{*}{0.5} & 0.92849 & 1 & Correct & 0.089681601 \\
\hline 17 & & 3.0091 & 3 & Correct & 0.238952656 \\
\hline 18 & & 4.8877 & 5 & Correct & 1.098657201 \\
\hline 19 & \multirow{3}{*}{0.6} & 0.74805 & 1 & Correct & 0.396830772 \\
\hline 20 & & 3.0635 & 3 & Correct & 0.151472078 \\
\hline 21 & & 4.7788 & 5 & Correct & 1.556553288 \\
\hline 22 & \multirow{3}{*}{0.7} & 0.73143 & 1 & Correct & 0.43610784 \\
\hline 23 & & 3.0838 & 3 & Correct & 0.123914315 \\
\hline 24 & & 4.7163 & 5 & Correct & 1.85528348 \\
\hline 25 & \multirow{3}{*}{0.8} & 0.69073 & 1 & Correct & 0.540117313 \\
\hline 26 & & 3.1322 & 3 & Correct & 0.069363738 \\
\hline 27 & & 4.5783 & 5 & Correct & 2.60769261 \\
\hline 28 & \multirow{3}{*}{0.9} & 0.66423 & 1 & Correct & 0.613811982 \\
\hline 29 & & 3.1864 & 3 & Correct & 0.026929652 \\
\hline 30 & & 4.5354 & 5 & Correct & 2.867625891 \\
\hline 31 & \multirow{3}{*}{1} & 0.54143 & 1 & Correct & 1.016809983 \\
\hline 32 & & 3.2751 & 3 & Correct & $2.71706 \mathrm{E}-06$ \\
\hline 33 & & 4.5193 & 5 & Correct & 2.968362953 \\
\hline 34 & \multirow{3}{*}{0.99} & 0.12217 & 0 & Correct & 0.077042033 \\
\hline 35 & & 3.101 & 2 & Incorrect & 4.183356226 \\
\hline 36 & & 4.3822 & 4 & Correct & 0.001922707 \\
\hline 37 & \multirow{3}{*}{0.44} & 0.17464 & 0 & Correct & 0.15742947 \\
\hline 38 & & 1.8491 & 2 & Correct & 0.638292632 \\
\hline 39 & & 4.0557 & 4 & Correct & 0.617232187 \\
\hline 40 & \multirow{3}{*}{0.53} & 0.07050 & 0 & Correct & 0.025655284 \\
\hline 41 & & 1.897 & 2 & Correct & 0.476245802 \\
\hline 42 & & 4.1954 & 4 & Correct & 0.219257557 \\
\hline 43 & \multirow{3}{*}{0.67} & 0.048248 & 0 & Correct & 0.012015925 \\
\hline 44 & & 2.1636 & 2 & Correct & 0.007123874 \\
\hline 45 & & 4.2598 & 4 & Correct & 0.103642597 \\
\hline
\end{tabular}

\begin{tabular}{|c|c|c|c|c|c|}
\hline 46 & \multirow{3}{*}{0.18} & 0.043976 & 0 & Correct & 0.009982287 \\
\hline 47 & & 1.9644 & 2 & Correct & 0.288343258 \\
\hline 48 & & 3.9067 & 4 & Correct & 1.263740691 \\
\hline 49 & \multirow{3}{*}{0.13} & 0.067706 & 0 & Correct & 0.023662079 \\
\hline 50 & & 1.9747 & 2 & Correct & 0.263759196 \\
\hline 51 & & 4.0143 & 4 & Correct & 0.77387227 \\
\hline 52 & \multirow{3}{*}{0.71} & $5.6419 \times 10^{-03}$ & 0 & Correct & 0.000164304 \\
\hline 53 & & 2.3178 & 2 & Correct & 0.070719865 \\
\hline 54 & & 4.3270 & 4 & Correct & 0.02864911 \\
\hline $\begin{array}{l}\text { Statis } \\
\% \text { NM } \\
\text { No. W } \\
\text { No. C } \\
\% \text { Su }\end{array}$ & $\begin{array}{l}=3 \\
=54 \\
=54 /\end{array}$ & & & & \\
\hline
\end{tabular}

Table 9: NN testing - Second test (All input loads are NOT trained and all No. of input broken bars are trained).

\begin{tabular}{|c|c|c|c|c|c|}
\hline No. & $\begin{array}{l}\text { Loading } \\
\text { level (pu) }\end{array}$ & $\begin{array}{l}\text { Detected No. } \\
\text { of BRB }\end{array}$ & $\begin{array}{l}\text { Actual No. } \\
\text { of BRB }\end{array}$ & Status & \%NMSE \\
\hline 1 & \multirow{3}{*}{0.52} & 0.92849 & 1 & Correct & 0.04230333 \\
\hline 2 & & 3.0091 & 3 & Correct & 0.034174895 \\
\hline 3 & & 4.8877 & 5 & Correct & 0.307402594 \\
\hline 4 & \multirow{3}{*}{0.14} & 0.95146 & 1 & Correct & 0.026013764 \\
\hline 5 & & 2.8202 & 3 & Correct & 0.302408599 \\
\hline 6 & & 4.9972 & 5 & Correct & 0.117531333 \\
\hline 7 & \multirow{3}{*}{0.22} & 1.1969 & 1 & Correct & 0.097987171 \\
\hline 8 & & 3.3459 & 3 & Correct & 0.217162556 \\
\hline 9 & & 5.1746 & 5 & Correct & 0 \\
\hline 10 & \multirow{3}{*}{0.41} & 0.55860 & 1 & Correct & 0.847313384 \\
\hline 11 & & 3.1871 & 3 & Correct & 0.02532026 \\
\hline 12 & & 4.7432 & 5 & Correct & 0.695035061 \\
\hline 13 & \multirow{3}{*}{0.57} & 0.72552 & 1 & Correct & 0.357509059 \\
\hline 14 & & 3.0615 & 3 & Correct & 0.006989071 \\
\hline 15 & & 4.8262 & 5 & Correct & 0.45331775 \\
\hline 16 & \multirow{3}{*}{0.64} & 0.78815 & 1 & Correct & 0.227421308 \\
\hline 17 & & 3.0583 & 3 & Correct & 0.008061296 \\
\hline 18 & & 4.7532 & 5 & Correct & 0.663186221 \\
\hline 19 & \multirow{3}{*}{0.77} & 1.3813 & 1 & Correct & 0.448076376 \\
\hline 20 & & 3.4364 & 3 & Incorrect & 0.410752528 \\
\hline 21 & & 5.01945 & 5 & Correct & 0.089897992 \\
\hline 22 & \multirow{3}{*}{0.85} & 0.75798 & 1 & Correct & 0.286429541 \\
\hline 23 & & 3.6953 & 3 & Incorrect & 1.30240205 \\
\hline 24 & & 4.8401 & 5 & Correct & 0.417867578 \\
\hline 25 & \multirow{3}{*}{0.97} & 1.4600 & 1 & Incorrect & 0.674819736 \\
\hline 26 & & 4.2336 & 3 & Incorrect & 4.758950766 \\
\hline 27 & & 5.0495 & 5 & Correct & 0.058446842 \\
\hline 28 & \multirow{3}{*}{0.62} & 0.77452 & 1 & Correct & 0.253237718 \\
\hline 29 & & 3.0589 & 3 & Correct & 0.007854427 \\
\hline 30 & & 4.7604 & 5 & Correct & 0.640717551 \\
\hline
\end{tabular}




\begin{tabular}{|c|c|c|c|c|c|}
\hline 31 & \multirow{3}{*}{0.93} & 1.8181 & 1 & Incorrect & 2.290707345 \\
\hline 32 & & 3.1836 & 3 & Incorrect & 0.023213449 \\
\hline 33 & & 4.9688 & 5 & Correct & 0.158174756 \\
\hline 34 & \multirow{3}{*}{0.44} & 0.8377 & 1 & Correct & 0.14526077 \\
\hline 35 & & 3.001669 & 3 & Correct & 0.039690625 \\
\hline 36 & & 4.89945 & 5 & Correct & 0.282738836 \\
\hline 37 & \multirow{3}{*}{0.67} & 1.13892 & 1 & Correct & 0.040393651 \\
\hline 38 & & 3.25519 & 3 & Correct & 0.084511409 \\
\hline 39 & & 5.04671 & 5 & Correct & 0.061082894 \\
\hline 40 & \multirow{3}{*}{0.18} & 0.908867 & 1 & Correct & 0.059340719 \\
\hline 41 & & 2.9879 & 3 & Correct & 0.051000942 \\
\hline 42 & & 4.7429 & 5 & Correct & 0.696002066 \\
\hline 43 & \multirow{3}{*}{0.71} & 1.24619 & 1 & Correct & 0.166694817 \\
\hline 44 & & 3.3863 & 3 & Correct & 0.29602381 \\
\hline 45 & & 5.0355 & 5 & Correct & 0.072260455 \\
\hline 46 & \multirow{3}{*}{0.82} & 1.301 & 1 & Correct & 0.26440575 \\
\hline 47 & & 3.7031 & 3 & Incorrect & 1.337034168 \\
\hline 48 & & 4.9261 & 5 & Correct & 0.230621195 \\
\hline 49 & \multirow{3}{*}{0.18} & 0.9088 & 1 & Correct & 0.059403818 \\
\hline 50 & & 2.9879 & 3 & Correct & 0.051000942 \\
\hline 51 & & 4.7429 & 5 & Correct & 0.696002066 \\
\hline 52 & \multirow{3}{*}{0.75} & 1.360957 & 1 & Correct & 0.396990586 \\
\hline 53 & & 3.4648 & 3 & Correct & 0.48411433 \\
\hline 54 & & 5.03359 & 5 & Correct & 0.074258514 \\
\hline \multicolumn{6}{|c|}{$\begin{array}{l}\text { Statistics: } \\
\% \text { NMSE }=0.4044 \% \\
\text { No. Wrongs }=3\end{array}$} \\
\hline
\end{tabular}

Table 10: NN testing - Third test (All input loads and all No. of input broken bars are NOT trained).

\section{Simulation Results}

Based on the built neural network, different simulations were performed to diagnose the broken bar fault occurrence under different loading levels. The first test has simulated different broken bars that are not trained, while all of the used loads are trained. The results indicated about $97 \%$ success rate, as only one case was wrongly estimated, as shown in Table 8.

In the second test, different loads were applied none of which were trained, while all broken bars were trained. The success rate was $94.7 \%$, due to three incorrectly estimated cases, as shown in Table 9.

In the last scenario, which was the worst case, none of the presented loads or broken bars was trained. The $92.98 \%$ success rate indicated that the network was unable to detect four cases properly, as shown in Table 10.

These simulation results indicate that the neural network based fault detection scheme is capable of detecting the broken rotor bars.

\section{Conclusion}

The purpose of this paper was to develop a monitoring method capable of detecting the broken bar faults in the LSPMS motor based on
Artificial Neural Network. This method was successfully classified the fault size based on the extracted features from the stator phase current using singular value decomposition method. In addition, this method was successfully applied to the designed LSPMSM. Three different tests were performed to assess the reliability of the built diagnosis system: The first test has simulated different broken bars that were not trained, while all the used loads were trained, achieving $97 \%$ accuracy, with only one wrongly estimated case. In the second test, different loads were applied, none of which were trained, while all broken bars were trained. The $94.7 \%$ success rate revealed three incorrectly estimated cases. In the last scenario, which was the worst case, none of the presented loads or broken bars was trained. The percentage of success was around $92.98 \%$, due to the network failing to detect four cases properly.

\section{References}

1. Taylor N (2001) Network effects of line start permanent magnet synchronous motors as replacements for induction motors. Royal Institute of Technology, Stockholm.

2. Hwang D, Young W, Sun J, Kim Y (2014) Robust Diagnosis Algorithm for Identifying Broken Rotor Bar Faults in Induction Motors. J Electr Eng Technol 8: $742-749$.

3. Pezzani C, Donolo P, Bossio G, Donolo M, Guzmán A, et al. (2014) Detecting Broken Rotor Bars With Zero-Setting Protection. IEEE Trans Ind Appl 50: 13731384.

4. Zarei J, Tajeddini MA, Hamid R (2014) Fault diagnosis of induction motors broken rotor bars by pattern recognition based on noise cancelation," in 2014 IEEE 23rd International Symposium on Industrial Electronics, ISIE 2014 A4 Bogazici University; IEEE Industrial Electronics Society (IES); The Institute of Electrical and Electronics Engineers (IEEE) pp: 2451-2456.

5. Guo-liang Z, Yun-bing W, Gang C (2012) Rotor break-bar fault diagnosis of Asynchronous motor Based on Empirical mode decomposition. 2012 AsiaPacific Power and Energy Engineering Conference.

6. Aydin I, Karakose M, Akin E (2011) A new method for early fault detection and diagnosis of broken rotor bars. Energy Conversion and Management 52 $1790-1799$.

7. Chen S (2008) Induction machine broken rotor bar diagnostics using prony analysis. Master thesis submitted to the school of electrical and electronics engineering, university of Adelaide pp: 1-127.

8. Shashidhara S, Raju S (2013) Tradeoff Analysis of Wavelet Transform Techniques for the Detection of Broken Rotor Bars in Induction Motors. Advance in Electronic and Electric Engineering 3: 1019-1030.

9. PuShi Z, Chen V, Zouaoui Z (2013) Optimal Wavelets for Broken Rotor Bars Fault Diagnosis," in 013 9th IEEE International Symposium on Diagnostics for Electric Machines, Power Electronics and Drives, SDEMPED 2013 A4 'Generalitat Valenciana-Conselleria d'Educacio, Cultura i Esport'; IEEE Power Electronics Society (PELS); SIEMENS; Universitat Pol, pages: 49-56.

10. Siddiqui KM, Giri V (2012) Broken Rotor Bar Fault Detection in Induction Motor Using Wavelet Transform. 2012 International Conference on Computing, Electronics and Electrical Technologies (ICCEET) pp: 1-6.

11. Mehrjou MR, Mariun N, Norhisam M, Radzi MAM (2015) Broken rotor ba detection in LS-PMSMs based on statistical features analysis of startup current envelope. IEEE International Conference on Smart Instrumentation, Measurement and Applications (ICSIMA), Putrajaya, Malaysia, November

12. Mehrjou MR, Mariun N, Karami M, Misron N, Mohd MA (2014) Performance analysis of line-start permanent magnet synchronous motor in presence of Rotor fault. IEEE Student Conference on Research and Development.

13. Mehrjou MR, Mariun N, Karami M, Misron N, Radzi MAM (2015) Broken Roto Bar Detection in LS-PMSMs Based on Statistical Features Analysis of Startup Current Envelope. Process of the 2015 IEEE 3rd international conference on smart instrumentation, measurements and applications (ICSIMA 2015), Malysia, Nov.

14. Mehrjou MR, Mariun N, Misron N, Radzi MAM (2016) Analysis of statistica features based on start-up current envelope for broken rotor bar fault detection in line start permanent magnet synchronous motor. Springer-Verlag Berlin Heidelberg. Electr Eng: 187-201. 
Citation: Baradieh K, Al-Hamouz Z, Abido M (2018) ANN Based Broken Rotor Bar Fault Detection in LSPMS Motors. J Electr Electron Syst 7: 273. doi: 10.4172/2332-0796.1000273

15. Hosseinzadeh M, Sadoughi A (2014) Conceptual comparison of LSPMS and induction machines for line-fed of different conditions. JWEET 3: 26-36.

16. Ong CM (1998) Dynamic simulation of electric machinary using MATLAB/ SIMULINK. UK, London: Prentice-Hall.

17. Hamdani S, Touhami O, Ibtiouen R (2008) A generalized two-axis model of a squirrel cage induction motor for rotor fault diagnosis. Serbian J Electrical Eng 5: $155-170$.

18. Drobnic K, LAvric H, Ambrozic V, Fiser R (2015) Flux linkages in squirrel-cage motor. 9th International Conference on Compatibility and Power Electronics (CPE).

19. Lipo TA, Garcia A (1998) Complex vector model of the squirrel cage induction machine including instantanous rotor bar currents. Conference Record of 1998 IEEE Industry Applications Conference. Thirty-Third IAS Annual Meeting.

20. Chen S, Zibvanovic R A novel-high resolution techniqe for induction machine broken bar detection. IEEE.

21. Ghate VN, Dudul SV (2011) Cascade neural-network-based fault classifier for three-phase induction motor. IEEE T Ind Electron 58: 1555-1563.
22. Karami M, Mariun N, Mehrjou MR, Kadir M, Misron N, et al. (2014) Static eccentricity fault recognition in three-phase line start permanent magne synchronous motor using finite element method. Mathematical Problems in Engineering.

23. May R, Dandy G, Maier H (2011) Review of input variable selection methods for artificial neural networks. Artificial Neural Networks - Methodological Advances and Biomedical Applications 2: 362-376.

24. Chebel-Morello B, Malinowski S, Senoussi H (2016) Feature selection for fault detection systems: application to the Tennessee Eastman process. Applied Intelligence 44: 111-122.

25. Zhang GP (2000) Neural networks for classification: a survey. IEEE Transactions on Systems, Man and Cybernetics 30: 451-462.

26. Basu JK, Bhattacharyya D, Kim T (2010) Use of Artificial Neural Network in Pattern Recognition. International J Software Engineering and Its Applications 4: 23-34.

27. Moradian M, Ebrahimi M, Danesh M, bayat M (2006) Detection of Broken Bars in Induction Motors Using a Neural Network. J Power Electron 6: 245-252. 